\title{
MODELING THE INTERDEPENDENCE OF VOLATILITY AND INTER-TRANSACTION DURATION PROCESSES
}

\author{
Joachim Grammig and Marc Wellner*
}

February 1999

\begin{abstract}
* Joachim Grammig is assistant professor of economics and Marc Wellner research assistant at the Johann Wolfgang Goethe-University of Frankfurt, Department of Economics
\end{abstract}

\begin{abstract}
In this paper we motivate, specify and estimate a model in which the intra-day volatilty process affects the inter-transaction duration process and vice versa. In order to solve the estimation problems implied by this interdependent formulation, we first propose a GMM estimation procedure for the Autoregressive Conditional Duration model. The method is then extended to the simultaneous estimation of the interdependent duration-volatility model. In an empirical application we utilize the model for an indirect test of the hypothesis that volatility is caused by private information that affects prices when informed investors trade. The result that volatility shocks significantly increase expected inter-transaction durations supports this hypothesis.
\end{abstract}

JEL classification: C32; C41; C51; G14

Keywords: Inter-transaction duration and volatility, financial market microstructure, ultrahigh frequency data, autoregressive conditional duration

Corresponding author:

Joachim Grammig

Faculty of Economics and Business Administration

Johann Wolfgang Goethe-University Frankfurt

Mertonstr. 17

60054 Frankfurt

Germany

grammig@wiwi.uni-frankfurt.de 


\section{INTRODUCTION ${ }^{1}$}

The accessibility of financial time series on the transaction level, labelled ultra high frequency data by Engle (1996), offered new perspectives to empirical finance and stimulated econometric model development. An essential benefit of ultra high frequency data is that it provides the appropriate basis for empirical tests of market microstructure theories and hypotheses, due to the availability on the micro-level where the theoretical models are originally formulated. A common feature of the market microstructure models proposed by Easley and O'Hara (1992), Diamond and Verrechia (1987), Glosten and Milgrom (1995), Hasbrouk (1988) and O'Hara (1995) is that the duration between events like transactions or quote updates contains information which affects the behavior of market makers and traders, and thus the price formation process. Hence, the possibility to exploit the information content of the inherent irregular spacing of financial transaction data in an empirical model is a big advantage, but it also involves methodological problems: With the exception of the econometric analysis of transition processes (Lancaster 1990), standard panel and time series models assume that the time interval between the observations is always of equal length. In order to provide an econometric framework for the analysis of irregularly spaced time series data, Engle and Russell (1998b) propose the Autoregressive Conditional Duration (ACD) model which combines elements from hazard rate and Autoregressive Conditional Heteroscedasticity (ARCH) models. ACD models have been exclusively employed to model financial transition processes such as quote updates and inter-transaction durations. Extensions and applications of ACD models have been provided by Bauwens and Giot (1998b), Coppejans and Domowitz (1998), Engle and Russell (1997), Ghysels and Jasiak (1998b), Grammig and Maurer (1998) and Meddahi, Renault and Werker (1998). Related approaches for modeling duration processes on financial markets have been proposed by Bisière and Kamionka (1998), Ghysels, Gouriéroux and Jasiak (1998) and Hautsch (1998).

Models for duration processes on financial markets become especially interesting if they are linked to the intra-day price process. Two classes of models can be distinguished: Bauwens and Giot (1998a) and Engle and Russell (1998a) model inter-transaction durations and discrete price movements in a multiple spell-competing risks framework. Hausman, Lo and

The authors thank the audiences at the UCL/CORE Econometrics Seminar, University of Louvain, at the Applied Economics and Econometrics Workshop, University of Mannheim, and at the Department of Finance Brown Bag seminar, University of Frankfurt/Main who offered helpful comments and suggestions. We are grateful to E. Ghysels for his readiness to answer most of our insistent questions, and to W. Haerdle and R. Hujer for offering insights into this work and supporting our project. Special thanks go to S. Kokot for taking part in programming the seasonality models, and to K. Maurer for his collaboration in the Monte Carlo study. Financial support is gratefully acknowledged from Roland Berger \& Partner, International Management Consultants, and the German Research Foundation (DFG). 
MacKinlay's (1992) ordered probit specification, which was extended by Gerhard, Hess and Pohlmeier (1997), shares the feature that discrete price movements depend on the length of the spell between successive transactions. However, the inter-transaction duration process is not recognized as endogenous. The second class of models focuses on modeling volatility and inter-transaction duration processes. The first approaches have been presented by Pai and Polasek (1995) and Engle (1996), who specifies a model that includes expected intertransaction durations, estimated using an ACD model, as additional explanatory variables in the conditional variance equation. Meddahi, Renault and Werker (1998) also propose a framework for the econometric modeling of volatility and duration processes, but as yet the empirical performance has only been tested for the duration part of the model. Ghysels and Jasiak (1998a) estimate a model where the volatility process depends on the inter-transaction durations process, but, unlike in Engle's (1996) approach, as the driver of the time variability of the parameters of a Generalized ARCH (GARCH) model ${ }^{2}$.

A common characteristic of these approaches is that a feedback of the volatility into the duration process is not considered. We will argue that this feature restricts empirical implementations and testing of market microstructure models. We therefore motivate, specify and estimate an interdependent model for volatility and inter-transaction duration processes. The paper has two main scopes: On the one hand, we aim to show the model's usability for empirical tests of market microstructure hypotheses: In an empirical study, the model is employed for an indirect test of the hypothesis that volatility is predominantly caused by private information which affects prices when informed investors trade. On the other hand, we want to address and propose a solution to the econometric problems implied by the interdependent specification. The challenge from the methodological point of view implied by the interdependent model is that the two step estimation procedure for volatility-duration models applied by Engle (1996) and Ghysels and Jasiak (1998a) is no longer applicable. This two step procedure consists of a first step estimation of an ACD model in order to produce a series of estimated conditional expected inter-transaction durations, which are used in the second step to estimate a GARCH model for irregularly spaced data. In the interdependent model that we propose, the volatility and the inter-transaction duration process evolve simultaneously. Since this has to be taken into account, the complexity of the - now inevitably simultaneous - parameter estimation procedure increases. As a convenient estimation

2 A new type of model is considered by Hafner (1998) who proposes a trivariate approach for intertransaction durations and transaction volumes processes on prices. 
framework for the interdependent model, we first propose a GMM estimation procedure for ACD models which is then extended to the simultaneous estimation of the interdependent duration-volatility model. In a Monte Carlo study, we assess the robustness of the GMM estimation procedure under various data generating processes. For the empirical application of the interdependent model, we use transaction data from the initial public offering (IPO) of a formerly state owned European telecommunication company. The dynamics of an IPO are found to provide an interesting environment to analyze the interaction of volatility and transaction intensity.

The remainder of this paper is organized as follows: In section 2.1, we outline the economic and statistical foundations of the interdependent duration-volatility model. A brief review of the ACD approach is provided in section 2.2. Section 2.3 contains the econometric formulation of the model. Estimation issues are addressed in section 3.1. Section 3.2 explains the ACD-GMM estimation approach, and section 3.3 the extension to the interdependent duration-volatility model. Results of a Monte Carlo study, carried out to assess the performance of the ACD-GMM estimation procedure, are reported in section 3.4. Section contains the empirical application. Background information on the IPO and the data generating process, as well as descriptive data analyses are reported in section 4.1. Section 4.2 contains the estimation results and their interpretations, as well as model simulations based on the estimated parameters. Section 5 concludes.

\section{ECONOMIC AND STATISTICAL FOUNDATIONS, AND ECONOMETRIC} SPECIFICATION

\subsection{Economic and stochastic processes to be considered for econometric modeling}

In this section, we outline the economic and statistical background for an interdependent duration-volatility model. Three building blocks will be considered: semi-strong market efficiency, time varying volatility persistence, and the feedback of the volatility process into the inter-transaction duration process.

\section{Semi strong market efficiency}

We assume semi-strong market efficiency which implies that the transaction price $y_{i}$ that is observable at time $t_{i}$ - i.e. the time at which two market participants agree to trade the security - can be written as the expectation of some "fundamental value" $\mathrm{y}^{*}$ conditional on public information available at time $t_{i}, F_{i}$ : 


$$
y_{i}=E\left(y^{*} \mid F_{i}\right)
$$

As this also holds for the following transaction at $\mathrm{t}_{\mathrm{i}+1}$, the expected return is,

$$
E\left(y_{i+1}-y_{i} \mid F_{i}\right)=E\left(r_{i+1} \mid F_{i}\right)=E\left\{E\left(y^{*} \mid F_{i+1}\right)-E\left(y^{*} \mid F_{i}\right) \mid F_{i}\right\}=0 \text {. }
$$

\section{Time varying volatility persistence}

Because shocks and news often occur in clusters, periods of turbulence are often encountered by financial markets after they have underwent times of calmness or side movement. This implies that despite returns retaining their martingale property [2], squared returns exhibit significant serial correlation. Standard econometric tools that are employed to account for this phenomenon of volatility persistence are ARCH type models which are heavily applied in empirical studies which analyze market microstructure processes. Bollerslev, Chou and Kroner (1992) provide a survey of the extensions to the standard models developed in the seminal papers by Engle (1982), Bollerslev (1986) and Taylor (1986). In order to apply ARCH models to ultra-high frequency data, the data is often thinned, aggregated or filtered in such a way that equally spaced data result. Recent contributions based on high frequency, but equally spaced data include the papers by Andersen and Bollerslev (1997, 1998), Covrig and Melvin (1998) and Paolella (1998).

For the scope of this paper, the irregular spacing of financial transaction data - trading of a security can take place at any time during the trading day - must remain intact, as it is the duration between two events which is assumed to contribute important information to the volatility process. In this paper, we adopt Ghysels and Jasiak's (1998a) idea to conceive the irregular spacing of the data as a continuously changing sampling frequency. This approach allows to utilize Drost and Nijman's (1993) and Drost and Werker's (1996) results on the temporary aggregation of GARCH processes, which extend related work on linear processes by Amemiya and Wu (1972), Harvey and Pierse (1984), Palm and Nijman (1984) and Lütkepohl (1986). The GARCH temporary aggregation formulae generalize Diebold's (1988) result who showed that conditional heteroskedasticity disappears if the sampling interval increases to infinity.

insert figure 1 about here

Figure 1 shows, how the parameters of a weak $\operatorname{GARCH}(1,1)$ that is sampled at a given frequency would change, if the same GARCH process were observed at a lower or higher 
frequency $^{3}$. It is obvious that the serial dependence of the GARCH process is no longer present if the sampling interval goes to infinity, which confirms Diebold's (1988) result. The intuition behind is that lagged conditional variances and squared returns that are available at $t_{i}$ do not contribute information for the forecast of the future squared return at $t_{i+1}$, if the time interval $t_{i+1}-t_{i}$, is large, because the effect of the events that occur within this spell dominate the effect of the information available at $t_{i}$.

\section{Feedback of the volatility process into the inter-transaction duration process}

We have outlined above, how inter-transaction durations influence the conditional variance (squared return forecast). The well known hypothesis, first stated by French and Roll (1986), that volatility is caused by the private information which affects prices when informed investors trade, implies the existence of an effect that works also in the opposite direction, i.e. that the inter transaction duration process depends on the volatility process. A direct indicator for the presence of private information (or informed trading) is of course not available in the data. If the hypothesis is valid, however, and volatility is an indicator for informed trade, then two arguments can be put forward, how and why volatility should affect the inter-transaction duration process:

In Easley et al.'s (1996) model, informed market participants enter the market only if private information is present which is not available to non-informed market participants. If only public information is present, the arrival rate of informed market participants is zero. The crucial assumption is that the arrival rate of non-informed traders is assumed to be constant, regardless whether private information is present or not. If volatility is caused by private information, then one would expect an higher transaction intensity if volatility is high and vice versa. This implies that the expected inter-transaction durations decrease. This effect is an outcome of Easley et al.'s (1996) assumption of an insensitive behavior of the noninformed market participants which arrive at a constant rate that is not affected by the presence of private information.

Dropping the assumption of insensitive non-informed market participants inverts the effect of volatility on expected inter-transaction durations: If non-informed market participants believe that volatility is caused by private information then it is most likely that non-informed market participants will exploit the information content of an observable volatility indicator. If this indicator signals informed trading, then the non-informed market participants will seek to

3 The definitions of weak, semi-strong and strong GARCH processes are given by Drost and Nijman (1993). The figure shows the results of the temporary aggregation formulae for flows. 
disclose the private information - by consulting analysts and information screens - and in the meantime avoid transactions with possibly better informed counterparts. This behavior to avoid adverse selection costs will slow the trading intensity down and cause longer expected durations between transactions.

It follows that if the hypothesis that volatility is caused by private information is valid, then a dependence of the inter-transaction duration process on the volatility process has to be considered, regardless whether we assume the non-informed market participants to be volatility insensitive or not. To summarize:

a) Assessing whether the feedback of the volatility into the duration process is economically and statistically significant (in either direction), provides an indirect test of the hypothesis that volatility is caused by private information. If the hypothesis is not true, then no feedback effect should be identifiable.

b) A significant positive feedback indicates that volatility is used as an measure for private information by non-informed market participants. A negative significant feedback suggests deficits in processing the (publicly available) information on volatility.

\subsection{The Autoregressive Conditional Duration model}

In the previous section, we have outlined the economic and statistical foundations of an interdependent model for volatility and inter-transaction duration processes. Before turning to the formulation of the econometric model in the next section, it is helpful to briefly review the econometric framework for modeling financial transition processes proposed by Engle and Russell (1998) as it will serve as another building block of the econometric model.

One obvious reason for the irregular spacing of transition process data from financial markets is the occurrence of events during the trading day which are known in advance, such as the opening and closing of international exchanges, lunch breaks, etc.. These events are responsible for a deterministic intra-day seasonality of the time interval between transactions, $\mathrm{x}_{\mathrm{i}} \equiv \mathrm{t}_{\mathrm{i}}-\mathrm{t}_{\mathrm{i}-1}$, the inter-transaction duration. Engle and Russell (1998) assume that the duration process $\mathrm{x}_{\mathrm{i}} \equiv \mathrm{t}_{\mathrm{i}}-\mathrm{t}_{\mathrm{i}-1}$ is decomposable into a stochastic component $\tilde{\mathrm{x}}_{\mathrm{i}}$, and a deterministic, diurnal factor $\Phi\left(\mathrm{t}_{\mathrm{i}-1}\right)$ which is dependent only on the time of day,

$$
\mathrm{x}_{\mathrm{i}}=\tilde{\mathrm{x}}_{\mathrm{i}} \cdot \Phi\left(\mathrm{t}_{\mathrm{i}-1}\right)
$$


Dividing the observed durations by the seasonal factor we obtain a series of diurnally adjusted durations $\tilde{\mathrm{x}}_{\mathrm{i}}=\frac{\mathrm{x}_{\mathrm{i}}}{\Phi\left(\mathrm{t}_{\mathrm{i}-1}\right)}$, with unconditional expectation $\mathrm{E}\left(\tilde{\mathrm{x}}_{\mathrm{i}}\right)=1.4$

The diurnally adjusted durations $\tilde{\mathrm{x}}_{\mathrm{i}}$ provide the starting point for the econometric formulation of the Autoregressive Conditional Duration (ACD) model. The key variable in the ACD approach is the expected normalized duration ${ }^{5}$ conditional on the information at time $t_{i}$, $\mathrm{E}\left(\tilde{\mathrm{x}}_{\mathrm{i}+1} \mid \mathrm{F}_{\mathrm{i}}\right) \equiv \psi_{\mathrm{i}+1}$, which is assumed to depend on past expected and realized adjusted durations and additional explanatory variables $\mathrm{z}_{\mathrm{i}}$, that may be suggested by market microstructure theories,

$$
\psi_{\mathrm{i}+1}=\omega_{\mathrm{d}}+\alpha_{\mathrm{d}, 1} \tilde{\mathrm{x}}_{\mathrm{i}}+\cdots+\alpha_{\mathrm{d}, \mathrm{q}} \tilde{\mathrm{x}}_{\mathrm{i}-\mathrm{q}+1}+\beta_{\mathrm{d}, 1} \psi_{\mathrm{i}}+\cdots+\beta_{\mathrm{d}, \mathrm{p}} \psi_{\mathrm{i}-\mathrm{p}+1}+\zeta_{\mathrm{i}}
$$

Engle and Russell's (1998) key assumption is that the standardized durations

$$
\frac{\tilde{\mathrm{x}}_{\mathrm{i}}}{\mathrm{f}\left(\psi_{\mathrm{i}}\right)}
$$

where $f(\cdot): R_{+} \rightarrow R_{+}$is a continuous function, are i.i.d. random variables with density function

$$
\mathrm{g}\left(\frac{\tilde{\mathrm{x}}_{\mathrm{i}}}{\mathrm{f}\left(\psi_{\mathrm{i}}\right)} \mid \mathrm{F}_{\mathrm{i}-1} ; \theta_{\mathrm{g}}\right)=\mathrm{g}\left(\frac{\tilde{\mathrm{x}}_{\mathrm{i}}}{\mathrm{f}\left(\psi_{\mathrm{i}}\right)} ; \theta_{\mathrm{g}}\right) .
$$

Engle and Russell (1998) propose assuming that $\tilde{\mathrm{x}}_{\mathrm{i}} \psi_{\mathrm{i}}^{-1}$ is $\operatorname{Exponential}(\lambda)$ under the restriction that $\lambda$ is equal to one,

$$
g\left(\frac{\tilde{x}_{i}}{\psi_{i}}\right)=\exp \left(-\frac{\tilde{x}_{i}}{\psi_{i}}\right)
$$

This specification produces the Exponential-ACD model. Less restrictive implied hazard functions can be achieved by assuming that $\tilde{\mathrm{x}}_{\mathrm{i}} \phi_{\mathrm{i}}^{-1}$, where

$$
\phi_{\mathrm{i}} \equiv \psi_{\mathrm{i}} \cdot[\Gamma(1+1 / \gamma)]^{-1}
$$

is Weibull $(\lambda, \gamma)$ under the restriction that the Weibull-distribution parameter $\lambda$ is equal to one,

$4 \quad$ Engle and Russell (1995a) implement this concept by assuming a linear spline function for the diurnal factor $\Phi\left(\mathrm{t}_{\mathrm{i}-1}\right)$ using hours as nodes, Engle and Russell (1998) use cubic splines.

5 To simplify the notation, we use the expression „,duration“ instead of ,diurnally adjusted durations“ if it is unambiguous to do so. 


$$
\mathrm{g}\left(\frac{\tilde{\mathrm{x}}_{\mathrm{i}}}{\phi_{\mathrm{i}}} ; \gamma\right)=\frac{\gamma \phi_{\mathrm{i}}}{\tilde{\mathrm{x}}_{\mathrm{i}}}\left(\frac{\tilde{\mathrm{x}}_{\mathrm{i}}}{\phi_{\mathrm{i}}}\right)^{\gamma} \exp \left[-\left(\frac{\tilde{\mathrm{x}}_{\mathrm{i}}}{\phi_{\mathrm{i}}}\right)^{\gamma}\right]
$$

This defines the Weibull-ACD model which nests an Exponential-ACD as a special case if $\gamma=1$.

\subsection{Econometric specification of the interdependent duration-volatility model}

Based on the economic and statistical foundations and the review of the ACD approach in the previous subsections, we now specify an interdependent econometric model for volatility and inter-transaction duration processes. As outlined in section 2.1, we adopt Ghysels and Jasiak's (1998a) idea to conceive the irregular spacing of transaction data to be a permanent change of the sampling frequency. Our rationale behind the econometric specification, however, differs from Ghysels and Jasiak's (1998): Consider a hypothetical situation in which all intertransaction durations are exactly equal to the value predicted by the diurnal factor $\Phi\left(\mathrm{t}_{\mathrm{i}}\right)$, i.e. all diurnally adjusted inter-transaction durations are equal to one. Expressed in transaction time, this implies that the data can be conceived as being equally spaced, or, equivalently, sampled at a constant frequency. We assume that in this hypothetical situation, the squared returns follow a weak $\operatorname{GARCH}(1,1)$ process:

$$
\mathrm{P}\left(\mathrm{r}_{\mathrm{i}+1}^{2} \mid \mathrm{r}_{\mathrm{i}}, \mathrm{r}_{\mathrm{i}-1}, \ldots\right)=\mathrm{h}_{\mathrm{i}+1}=\varpi_{\mathrm{h}}+\alpha_{\mathrm{h}} \cdot \mathrm{r}_{\mathrm{i}}^{2}+\beta_{\mathrm{h}} \cdot \mathrm{h}_{\mathrm{i}}
$$

where $P\left(r_{i+1}^{2} \mid r_{i}, r_{i-1}, \ldots\right)$ denotes the best linear predictor in terms of $\left(1, r_{i-1}, r_{i-2}, \ldots, r_{i-1}^{2}, r_{i-2}^{2}, \ldots\right){ }^{6}$ Because the inter-transaction durations (expressed in calendar time) are exactly equal to the values predicted by the deterministic diurnal component, we will denote the weak GARCH process in equation [10] as "normal duration GARCH process". Although the normal duration GARCH process is virtually unobservable in reality, it is pivotal for the model specification. The question that we need to answer is, how the properties of the normal duration GARCH process will be affected if the inter-transaction durations differ from the diurnal component $\Phi\left(\mathrm{t}_{\mathrm{i}}\right)$. To address this issue, we maintain the assumption that up to time $t_{i}$, the inter-transaction durations had been equal to the diurnal factor. If at time $t_{i}$ the next inter-transaction duration is expected to be higher than predicted by the diurnal factor, i.e. $\psi_{\mathrm{i}+1}>1$, we can conceive this as an expected aggregation of the normal duration GARCH

6 Different to a semi-strong GARCH process, where $h_{i}$ is defined as a conditional variance, $h_{i}$ in a weak GARCH process is defined as the best linear predictor of $r_{i}^{2}$ in terms of $1, r_{i-1}, r_{i-2}, \ldots, r_{i-1}^{2}, r_{i-2}^{2}, \ldots .$. , i.e.: $E\left(r_{i}^{2}-P\left(r_{i}^{2} \mid r_{i-1}, r_{i-2}, \ldots\right)\right) r_{i-n}^{1}=0$, for $i \geq 1$ and $1=0,1,2$. See Drost and Nijman (1993) for details. 
process to a lower sampling frequency. An expected inter-transaction duration that is smaller than predicted by $\Phi\left(\mathrm{t}_{\mathrm{i}}\right)$, i.e. $\psi_{\mathrm{i}+1}<1$, implies that the expected sampling frequency is higher than for the normal duration GARCH process. After the next transactions at $t_{i+1}, t_{i+2}, \ldots$, the expected inter-transaction durations will most likely be revised again. The normal duration GARCH process in equation [10] is therefore subject to a permanent change of expected sampling frequencies. For the econometric specification, we can now utilize Drost and Nijman's (1993) temporary aggregation formulae for weak GARCH processes, and obtain a GARCH(1,1) model with time varying parameters which depend on expected intertransaction duration,

$$
\mathrm{h}_{\mathrm{i}+1}=\varpi_{\mathrm{DN}}\left(\psi_{\mathrm{i}+1}, \theta_{\mathrm{h}}\right)+\alpha_{\mathrm{DN}}\left(\psi_{\mathrm{i}+1}, \theta_{\mathrm{h}}\right) \cdot \mathrm{r}_{\mathrm{i}}^{2}+\beta_{\mathrm{DN}}\left(\psi_{\mathrm{i}+1}, \theta_{\mathrm{h}}\right) \cdot \mathrm{h}_{\mathrm{i}}
$$

where $\theta_{\mathrm{h}}=\left(\omega_{\mathrm{h}}, \alpha_{\mathrm{h}}, \beta_{\mathrm{h}}, \kappa_{\mathrm{h}}\right)^{\prime}$, and $\kappa_{\mathrm{h}}$ denotes the kurtosis of the return distribution ${ }^{7}$. The terms $\varpi_{\mathrm{DN}}\left(\psi_{\mathrm{i}+1}, \theta_{\mathrm{h}}\right), \alpha_{\mathrm{DN}}\left(\psi_{\mathrm{i}+1}, \theta_{\mathrm{h}}\right)$ and $\beta_{\mathrm{DN}}\left(\psi_{\mathrm{i}+1}, \theta_{\mathrm{h}}\right)$ denote the elements of Drost and Nijman's (1993) temporary aggregation formulae for symmetric weak GARCH processes. Appendix A-2 contains the exact formulae to be used as well as the theorem that justifies their application using arbitrary real aggregation parameters $\psi_{\mathrm{i}+1} \cdot{ }^{8}$

Equation [11] describes how the volatility model depends on expected inter-transaction durations. In section 2.1, we have identified economic processes that necessitate modeling also the feedback, i.e. the dependence of the duration process on the volatility process. In order to implement the concept in an econometric model, we assume that the diurnally adjusted inter-transaction durations follow a semi-strong ACD process. ${ }^{9}$ Since it is a-priori uncertain whether it is expected or unexpected volatility which may induce the economic processes outlined in section 2.1, we include two volatility indicators as additional explanatory variables in the ACD model's conditional expected duration equation. The first is $\mathrm{h}_{\mathrm{i}}$ - the "expected volatility component" - and the second is the ratio of the squared return and $\mathrm{h}_{\mathrm{i}}$ - the "volatility shock component". The conditional expected duration equation takes on the form:

7 More precisely, the kurtosis $\kappa_{\mathrm{h}}$ is associated with a distribution of returns that are measured in the hypothetical situation that the normalized durations are all equal to one. For identification purposes, $\kappa_{\mathrm{h}}$ is not treated as a parameter to be estimated but fixed on the kurtosis of the normal distribution.

Drost and Nijman's (1993) temporary aggregation formulae hold only for weak GARCH(1,1) processes. Strong and semi-strong GARCH processes do not temporary aggregate. 


$$
\psi_{\mathrm{i}+1}=\omega_{\mathrm{d}}+\alpha_{\mathrm{d}, 1} \widetilde{\mathrm{x}}_{\mathrm{i}}+\cdots+\alpha_{\mathrm{d}, \mathrm{q}} \tilde{\mathrm{x}}_{\mathrm{i}-\mathrm{q}+1}+\beta_{\mathrm{d}, 1} \psi_{\mathrm{i}}+\cdots+\beta_{\mathrm{d}, \mathrm{p}} \psi_{\mathrm{i}-\mathrm{p}+1}+\zeta_{1} \mathrm{~h}_{\mathrm{i}}+\zeta_{2} \frac{\mathrm{r}_{\mathrm{i}}^{2}}{\mathrm{~h}_{\mathrm{i}}}
$$

It follows from our theoretical considerations in section 2.1 that either a statistically and economically significant positive or negative sign of the slope parameters $\zeta_{1}$ and $\zeta_{2}$ would be compatible with the hypothesis that volatility is caused by private information. Equations [11] and [12] constitute the interdependent duration-volatility model. We now turn to the estimation issues involved by this specification.

\section{ESTIMATION ISSUES}

\subsection{Estimation of recursive volatility-duration models}

Despite the fact that in Engle's (1996) model the expected inter-transaction durations affect conditional heteroskedasticity in a different way, this and Ghysels and Jasiak's (1998a) approach share a common feature. Both employ the Autoregressive Conditional Duration model to produce a forecast for the conditional expected duration, $\psi_{i+1}$, which is needed for the squared return forecast $h_{i+1}$. The crucial point is that both approaches do not consider a feedback from the volatility into the inter-transaction duration process. This assumption significantly facilitates parameter estimation, because the procedure can be separated into two parts. The first step consists of an estimation of an Autoregressive Conditional Duration model and the computation of a series of estimated conditional expected durations, $\left\{\hat{\psi}_{\mathrm{i}}\right\}_{1}^{\mathrm{T}}$. In the second step, this series is then used for the estimation of the parameters of a GARCH model for irregularly spaced data. Engle (1996) and Ghysels and Jasiak (1998a) use ML estimators in both steps. The interdependent model in equations [11] and [12] precludes the application of the two step estimation procedure, since the interdependent evolution of the series $h_{i}$ and $\psi_{i}$ has to be taken into account. In order to provide a simultaneous estimation procedure for the interdependent model, we first derive the orthogonality conditions for Generalized Method of Moments (GMM) estimation of the Autoregressive Conditional Duration model in section 3.2 which is then extended for simultaneous estimation in section 3.3 .

\subsection{Orthogonality conditions for a GMM estimation of the ACD model}

With the exception of Meddahi, Renault and Werker's (1998) approach, the Maximum Likelihood method has exclusively been used to estimate the parameters of Autoregressive Conditional Duration models, as e.g. in Engle (1996), Ghysels and Jasiak (1998a), Engle and 
Russell (1995a, 1997, 1998) and Bauwens and Giot (1998b). The GMM approach proposed in the following does not deliver estimates for the distribution parameters of the ACD model, which implies that survior or hazard functions cannot be estimated. However, since only an estimate of the parameter vector $\theta_{\mathrm{d}}=\left(\omega_{\mathrm{d}}, \alpha_{\mathrm{d}, 1}, \alpha_{\mathrm{d}, 2}, \ldots, \alpha_{\mathrm{d}, \mathrm{q}}, \beta_{\mathrm{d}, 1}, \beta_{\mathrm{d}, 2}, \ldots, \beta_{\mathrm{d}, \mathrm{p}}\right)^{\prime}$ is needed, this is no restriction as long as $\theta_{\mathrm{d}}$ can be estimated consistently and with acceptable efficiency. The results of a Monte Carlo study designed to assess the performance of the GMM- compared to ML-estimation of ACD models are reported in section 3.4. After deriving orthogonality conditions for the ACD-GMM estimation, we provide the orthogonality conditions for the simultaneous estimation of the interdependent model proposed in the previous section.

Using the definitions of strong, semi-strong and weak ACD processes in appendix A-1, we are able to derive a set of orthogonality conditions which provide the basis for the GMM estimation of the ACD model. Regardless of the type of ACD process, we can utilize the serial independence (strong ACD) or zero autocorrelation (semi strong and weak ACD) assumption for the standardized durations $\tilde{\mathrm{x}}_{\mathrm{i}} \psi_{\mathrm{i}}^{-1}$ to obtain the following $\mathrm{J}+1$ orthogonality conditions,

$$
\begin{aligned}
& E\left\{f_{d, 1,1}\left(\theta_{d}, v_{i}\right)\right\}=E\left(\frac{\tilde{x}_{i}}{\psi_{i}}-1\right)=0 \\
& E\left\{f_{d, 1, j+1}\left(\theta_{d}, v_{i}\right)\right\}=E\left\{\left(\frac{\tilde{x}_{i}}{\psi_{i}}-1\right)\left(\frac{\tilde{x}_{i-j}}{\psi_{i-j}}-1\right)\right\}=0 \text { for } j=1, \ldots, J,
\end{aligned}
$$

where $\mathrm{v}_{\mathrm{i}}$ denotes a vector of variables observable at time $\mathrm{t}_{\mathrm{i}}$. Using the weak ACD process definition (appendix A-1), we can derive additional orthogonality conditions utilizing the assumption that the implicit error in forecasting the duration at $t_{i+1}$,

$$
\mathrm{w}_{\mathrm{d}, \mathrm{i}+1}=\tilde{\mathrm{x}}_{\mathrm{i}+1}-\psi_{\mathrm{i}+1}
$$

is uncorrelated with the lagged durations,

$$
E\left\{f_{d, 2}\left(\theta_{d}, v_{i}\right)\right\}=E\left(w_{d, i+1} Z_{d, i}\right)=0
$$

where

$$
\mathrm{Z}_{\mathrm{d}, \mathrm{i}}=\left(1, \tilde{\mathrm{x}}_{\mathrm{i}}, \tilde{\mathrm{x}}_{\mathrm{i}-1}, \ldots, \tilde{\mathrm{Z}}_{\mathrm{d}, \mathrm{i}}^{\prime}\right)^{\prime}
$$

$\tilde{Z}_{\mathrm{d}, \mathrm{i}}$ denotes a vector of additional variables assumed to be uncorrelated with the forecasting error $\mathrm{w}_{\mathrm{d}, \mathrm{i}+1}$. The orthogonality conditions in equations [13], [14] and [16] provide the basis 
for the GMM estimation of the ACD model to which we come back later. We now turn to the simultaneous GMM estimation of the interdependent volatility-duration model.

\subsection{Simultaneous GMM estimation}

Orthogonality conditions for the volatility equation of the interdependent model in equations [11] and [12] can be derived from Drost and Nijman's (1993) definition of weak GARCH processes which is characterized by the assumption that the implicit error in forecasting the squared return,

$$
\mathrm{w}_{\mathrm{h}, \mathrm{i}+1}=\mathrm{r}_{\mathrm{i}+1}^{2}-\mathrm{h}_{\mathrm{i}+1} \text {, }
$$

is uncorrelated with lagged returns and squared returns. The implied orthogonality conditions have been outlined by Bates and White (1988), Ghysels and Jasiak (1998a), Hamilton (1994) and Rich, Raymond and Butler (1991),

$$
\mathrm{E}\left\{\mathrm{f}_{\mathrm{h}, 1}\left(\theta, \mathrm{v}_{\mathrm{i}}\right)\right\}=\mathrm{E}\left(\mathrm{w}_{\mathrm{h}, \mathrm{i}+\mathrm{1}} \mathrm{Z}_{\mathrm{h}, \mathrm{i}}\right)=0
$$

where

$$
\mathrm{Z}_{\mathrm{h}, \mathrm{i}}=\left(1, \mathrm{r}_{\mathrm{i}}, \mathrm{r}_{\mathrm{i}-1}, \ldots, \mathrm{r}_{\mathrm{i}}^{2}, \mathrm{r}_{\mathrm{i}-1}^{2}, \ldots . \tilde{\mathrm{Z}}_{\mathrm{h}, \mathrm{i}}^{\prime}\right)^{\prime}
$$

$\widetilde{\mathrm{Z}}_{\mathrm{h}, \mathrm{i}}$ denotes a vector of additional instruments that are assumed to be uncorrelated with the forecasting error $\mathrm{w}_{\mathrm{h}, \mathrm{i}+1}$. The parameter vector $\theta=\left(\omega_{\mathrm{h}}, \alpha_{\mathrm{h}}, \beta_{\mathrm{h}}, \theta_{\mathrm{d}}^{\prime}, \zeta_{1}, \zeta_{2}\right)^{\prime}$ also includes the parameters from the conditional duration equation, since in the interdependent model in equations [11] and [12], the time varying GARCH parameters depend on the parameters of the conditional expected duration equation and vice versa.

The weak market efficiency assumption implies additional orthogonality conditions of the form

$$
\mathrm{E}\left\{\mathrm{f}_{\mathrm{m}, 1}\left(\theta, \mathrm{v}_{\mathrm{i}}\right)\right\}=\mathrm{E}\left(\mathrm{r}_{\mathrm{i}+1} \mathrm{Z}_{\mathrm{m}, \mathrm{i}}\right)=0
$$

where

$$
\mathrm{Z}_{\mathrm{m}, \mathrm{i}}=\left(1, \mathrm{r}_{\mathrm{i}}, \mathrm{r}_{\mathrm{i}-1}, \ldots . . \tilde{\mathrm{Z}}_{\mathrm{m}, \mathrm{i}}^{\prime}\right)^{\prime}
$$

is a vector of lagged returns and other instruments available at $t_{i}$ that are assumed to be uncorrelated with the return at $\mathrm{t}_{\mathrm{i}+1}$. 
It is now possible to collect the orthogonality conditions for the duration and the volatility part of the model,

$$
\begin{aligned}
& E\left\{f_{m, 1}\left(\theta, v_{i}\right)\right\}=E\left(r_{i+1} Z_{m, i}\right)=0 \\
& E\left\{f_{h, 1}\left(\theta, v_{i}\right)\right\}=E\left(w_{h, i+1} Z_{h, i}\right)=0 \\
& E\left\{f_{d, 1,1}\left(\theta, v_{i}\right)\right\}=E\left(\frac{\tilde{x}_{i}}{\psi_{i}}-1\right)=0 \\
& E\left\{f_{d, 1, j+1}\left(\theta, v_{i}\right)\right\}=E\left\{\left(\frac{\tilde{x}_{i}}{\psi_{i}}-1\right)\left(\frac{\tilde{x}_{i-j}}{\psi_{i-j}}-1\right)\right\}=0 \text { for } j=1, \ldots, J \\
& E\left\{f_{d, 2}\left(\theta, v_{i}\right)\right\}=E\left(w_{d, i+1} Z_{d, i}\right)=0,
\end{aligned}
$$

where

$$
\mathrm{Z}_{\mathrm{d}, \mathrm{i}}=\left(1, \tilde{\mathrm{x}}_{\mathrm{i}}, \tilde{\mathrm{x}}_{\mathrm{i}-1}, \ldots, \mathrm{r}_{\mathrm{i}}^{2}, \mathrm{r}_{\mathrm{i}-1}^{2}, \ldots . \tilde{\mathrm{Z}}_{\mathrm{d}, \mathrm{i}}^{\prime}\right)^{\prime}
$$

Because of the model's interdependency, the ACD orthogonality conditions in equations [25] - [27] are a function of all the model parameters, and the vector of instruments $Z_{\mathrm{d}, \mathrm{i}}$ is now augmented with lagged squared returns. The parameter estimation must be carried out simultaneously, since computation of $h_{i}$ requires the availability of the conditional expected duration $\psi_{\mathrm{i}}$, and in order to compute $\psi_{\mathrm{i}}, \mathrm{h}_{\mathrm{i}-1}$ is needed. Both $\psi_{\mathrm{i}}$ and $\mathrm{h}_{\mathrm{i}}$ depend on the parameter vector $\theta=\left(\theta_{\mathrm{d}}^{\prime}, \omega_{\mathrm{h}}, \alpha_{\mathrm{h}}, \beta_{\mathrm{h}}\right)^{\prime}$. In order to carry out the simultaneous estimation, we collect the GMM disturbances in a vector

$$
\begin{aligned}
& \mathrm{f}\left(\theta, \mathrm{v}_{\mathrm{i}}\right)= \\
& \left\{\mathrm{f}_{\mathrm{d}, 1,1}\left(\theta, \mathrm{v}_{\mathrm{i}}\right), ., \mathrm{f}_{\mathrm{d}, 1, \mathrm{~J}+1}\left(\theta, \mathrm{v}_{\mathrm{i}}\right), \mathrm{f}_{\mathrm{d}, 2}\left(\theta, \mathrm{v}_{\mathrm{i}}\right), \mathrm{f}_{\mathrm{h}, 1}\left(\theta, \mathrm{v}_{\mathrm{i}}\right), \mathrm{f}_{\mathrm{m}, 1}\left(\theta, \mathrm{v}_{\mathrm{i}}\right)^{\prime}\right\}^{\prime}
\end{aligned}
$$

and define the sample means of $\mathrm{f}\left(\theta, \mathrm{v}_{\mathrm{i}}\right)$ as

$$
\mathrm{g}\left(\theta ; \mathrm{S}_{\mathrm{T}}\right)=\mathrm{T}^{-1} \sum_{\mathrm{i}=1}^{\mathrm{T}} \mathrm{f}\left(\theta ; \mathrm{v}_{\mathrm{i}}\right)
$$

where $\mathrm{S}_{\mathrm{T}}=\left(\mathrm{v}_{\mathrm{T}}^{\prime}, \mathrm{v}_{\mathrm{T}-1}^{\prime}, \ldots \mathrm{v}_{1}^{\prime}\right)$ contains the observations of a sample size $\mathrm{T}$. A consistent estimate $\hat{\theta}$ is obtained by minimizing

$$
\mathrm{Q}\left(\theta ; \mathrm{S}_{\mathrm{T}}\right)=\mathrm{g}\left(\theta ; \mathrm{S}_{\mathrm{T}}\right)^{\prime} \mathrm{W}_{\mathrm{T}} \mathrm{g}\left(\theta ; \mathrm{S}_{\mathrm{T}}\right)
$$


with respect to $\theta$, where $\mathrm{W}_{\mathrm{T}}$ is a positive-semidefinite weighting matrix which satisfies $\lim _{\mathrm{T} \rightarrow \infty} \mathrm{W}_{\mathrm{T}}=\mathrm{W}_{0}$. In order to ensure stationarity and non-negativity of the $\mathrm{h}_{\mathrm{i}}$ and $\psi_{\mathrm{i}}$-series, it is required that the maximization is carried out subject to the constraints

$$
\begin{aligned}
& \varpi_{\mathrm{h}}>0 \\
& \alpha_{\mathrm{h}}+\beta_{\mathrm{h}}<1 \\
& \varpi_{\mathrm{d}}>0 \\
& \sum_{\mathrm{j}=1}^{\mathrm{q}} \alpha_{\mathrm{d}, \mathrm{q}}+\sum_{\mathrm{j}=1}^{\mathrm{p}} \beta_{\mathrm{d}, \mathrm{p}}<1 .
\end{aligned}
$$

When computing an estimate for the minimum asymptotic variance weighting matrix $\mathrm{W}_{\mathrm{T}}=\Omega^{-1}$, where

$$
\Omega=\lim _{\mathrm{T} \rightarrow \infty} \cdot \mathrm{E}\left[\mathrm{g}\left(\theta ; \mathrm{S}_{\mathrm{T}}\right) \cdot \mathrm{g}\left(\theta ; \mathrm{S}_{\mathrm{T}}\right)^{\prime}\right]
$$

it must be taken into account that the vector process $\left\{f\left(\theta, v_{i}\right)\right\}_{i=-\infty}^{\infty}$ is serially correlated. Hence, we use an autocorrelation consistent estimator such as the one proposed by Newey and West (1987) ${ }^{10}$,

$$
\begin{aligned}
& \hat{\Omega}=\hat{\Gamma}_{0, \mathrm{~T}}+\sum_{v=1}^{\mathrm{M}}\left(1-\frac{\mathrm{v}}{\mathrm{M}+1}\right)\left(\hat{\Gamma}_{\mathrm{v}, \mathrm{T}}+\hat{\Gamma}_{\mathrm{v}, \mathrm{T}}^{\prime}\right) \\
& \hat{\Gamma}_{\mathrm{v}, \mathrm{T}}=\mathrm{T}^{-1} \sum_{\mathrm{i}=\mathrm{v}+1}^{\mathrm{T}}\left[\mathrm{f}\left(\hat{\theta}, \mathrm{v}_{\mathrm{i}}\right)\right] \cdot\left[\mathrm{f}\left(\hat{\theta}, \mathrm{v}_{\mathrm{i}-\mathrm{v}}\right)\right]^{\prime}
\end{aligned}
$$

If only an estimate of the ACD model is needed, the procedure outlined above can be applied by using only the orthogonality conditions [13], [14] and [16]. Conditional expected durations must then be computed using eq. [4].

\subsection{Monte Carlo study}

We test the robustness of the ACD-GMM procedure outlined in the previous subsection in a Monte Carlo study in which two data generating processes are taken into account: The first is

10 Alternative estimators have been proposed by Gallant (1987), Andrews (1991), Andrews and Monahan (1992), and West (1997). The standard GMM estimation algorithm is applied which consists of obtaining initial estimates of the parameters $\theta$ by choosing $\mathrm{W}_{\mathrm{T}}=\mathrm{I}$. The initial estimate for $\theta$ is used to compute the weighting matrix $\hat{\Omega}$ which is then used to obtain an updated estimate $\hat{\theta}$. The procedure is repeated until convergence. We have written programs for the GMM estimation of ACD models and the interdependent duration-volatility model in GAUSS. These algorithms require the Constraint Optimization module. 
an (strong) Exponential-ACD $(1,1)$ process where $\varpi_{\mathrm{d}, 1}=0.2, \alpha_{\mathrm{d}, 1}=0.1$, and $\beta_{\mathrm{d}, 1}=0.7$, and the second a (strong) Weibull-ACD $(1,1)$ with identical parameters, and $\gamma=0.6$. The parameter values are chosen so that they are similar to those found in empirical applications of ACD models. For the ACD-GMM estimation, we set the lag order J in eq. [14] equal to 24. Past durations up to lag 12 are used as instruments in eq. [17]. The lag order $M$ in eq. [37] is set to 6. For each DGP we simulate 1000 replications of the particular ACD process with 15000 observations in each sample and estimate the model parameters using the Maximum Likelihood method - employing the likelihood function that matches with the true DGP - and the GMM procedure proposed in the previous subsection. Table 1 reports mean, variance, mean squared error, mean absolute error, and the quantiles of the distributions of the estimated parameters. In order to provide a graphical comparison of the distributions of the ML and GMM estimated parameters, figures 2 and 3 depict kernel density plots.

insert table 1 about here

The Monte Carlo results confirm that the GMM estimation procedure proposed above produces parameter estimates that are quite close to those obtained by the ML estimation using the likelihood function of the true DGP. Root mean squared errors, mean and median absolute errors produced by the GMM estimation can be considered small and comparable to the ML estimation results, especially for the case where the DGP is an Exponential ACD process. Comparing the kernel plots in figure 2 for the Exponential ACD-DGP, the distributions produced by the ML and GMM estimators appear similar. The difference in distributions is larger in the case of the Weibull-ACD DGP, with a somewhat flatter and skewed distribution of the GMM estimates (figure 3).

insert figure 2 about here

insert figure 3 about here

\section{EMPIRICAL APPLICATION}

\subsection{Data}

\subsubsection{The Deutsche Telekom IPO}

To perform an empirical application of the interdependent model and estimation procedures developed in the previous sections, we use transaction data from the first 5 weeks of the November 1996 Deutsche Telekom initial public offering (IPO), the first step of the largest 
ever privatization project in Germany. With Deutsche and Dresdner Bank as well as Goldman Sachs as global coordinators and unprecedented marketing efforts, the first tranche of 713 million shares, about $25 \%$ of the total shares of the formerly $100 \%$ state owned telecommunication monopolist, was offered to private investors. Special incentive programs for private households, including price reductions and bonus issues, led to a 5-6 fold oversubscription. 23 million of the offered shares were distributed among the Telekom's employees. The remaining shares were bought by German private (174 million shares) and institutional investors (254 million shares). International investors were located in the USA (14\% of shares), the UK ( $8 \%$ of shares), other Europe (6\% of shares) and Asia (5\% of shares). The issue price was 28.5 DEM (18.89 USD) per share resulting in total issue proceeds of 13.3 billion USD. Nov 18, 1996 was the first day the Deutsche Telekom share traded on the Frankfurt and New York stock exchanges. In Tokyo, trading started one day later. Due to expected extraordinary trading intensity, the trading hours of the German electronic trading system (IBIS) were extended from 08:30 $\mathrm{h}-17: 00 \mathrm{~h}$ to 08:30 $\mathrm{h}-19: 00 \mathrm{~h}$. Deutsche Telekom was immediately included in the DAX, the top 30 blue chip index for German stocks, ranking as number 9 in terms of market capitalization.

\subsubsection{The data generating process}

Transaction data of the Telekom IPO is obtained from the electronic trading system IBIS (short for "Integrated Stock Exchange Trading and Information System"). IBIS is an electronic market in which participants trade securities in an interactive double auction framework $^{11}$. A trader is able to view the complete system order book for the securities of interest on a computer screen, where price ascending bids and price descending asks, including the volume of each bid and ask, are displayed. Market participants can enter and delete their bids and asks in the electronic order book, but the quotes entered in the system are binding. As the system does not automatically match quotes, a transaction must always be initiated by a market participant who is willing to sell to the bid side or buy from the ask side. A trader willing to buy from the order book is restricted to hitting the cheapest ask unless the volume that the initiator wants to buy is smaller or larger than the volume offered by the cheapest ask and this offer to sell the security contains a special mark indicating that the supplier of the ask is only willing to trade the volume entered in the system (and not less). In this case the initiating buyer is allowed to hit the next ask in the order book. A buying initiator can simultaneously select more than one asks from the list, under the condition that they are

11 In 1997 IBIS was replaced by its successor system named XETRA which retained the same basic functionality. 
chosen in the correct price ascending order ${ }^{12}$. Each observation in the data contains the transaction price, the transaction volume, the security ID and the date and time of the transaction with an accuracy in hundredths of seconds. If a trader has initiated a transaction by hitting more than one of the asks or bids within a very short time period, the database contains the sub-transactions (each bid or ask hit) as separate observations, because the entries in the electronic order book may have been entered by different market participants requiring separate settlement. Of course, the recorded time interval between the sub-transactions of a "split transaction" is very short (but always nonzero). The algorithm applied to consolidate split transactions is contained in appendix A-3.

\subsubsection{Data filtering and descriptive analyses}

The split transaction consolidated sample contains 12057 transactions of the Deutsche Telekom security between Nov 18, 1996 and Dec 20, 1996. We exclude the first transaction of each day (otherwise the inter-transaction duration, $\mathrm{x}_{\mathrm{i}} \equiv \mathrm{t}_{\mathrm{i}}-\mathrm{t}_{\mathrm{i}-1}$, would cover the non trading time between the days) and transactions during the prolonged trading hours of the first Deutsche Telekom trading week. We also remove the observation immediately after a system breakdown on Dec13, 1996 between 09:00 a.m. and 10:30 a.m.. The following adjustments to the raw data inter-transaction durations and returns are carried out:

- In order to account for duration diurnality, we follow Engle and Russell (1998) and estimate cubic spline functions using half hours as nodes and diurnally adjust the durations as described in section 2.2. As the diurnal duration factor varies with different types of trading days, we fit separate splines for the weekdays, US-holidays and expiry dates at the Frankfurt futures and options exchange.

- In order to obtain return series which is free of the bid ask bounce that affects financial transaction prices, we compute the residuals of an $\operatorname{ARMA}(2,0)$ model for returns ${ }^{13}$. Having obtained the white noise ARMA residual, intra-day volatility seasonality is accounted for by applying the method proposed by Andersen and Bollerslev (1997).

insert figure 4 about here

insert figure 5 about here

Figures 4 and 5 depict the resulting adjusted return (in DEM/100) and squared return series. The empirical mean and variance of the adjusted return (adjusted duration) series are equal to

12 For a seller willing to hit the bids in the electronic order book, the same logic applies.

13

The lack of best bids and asks in the data precludes using mid-quotes. 
-0.002 (1.009) and 4.926 (1.746), and the skewness and kurtosis are 0.103 (3.225) and 4.067 (17.551). In order to get an impression of the distribution of durations and returns in the sample, figures 6 and 7 depict kernel density plots for the adjusted duration and return series.

insert figure 6 about here

insert figure 7 about here

\subsection{Estimation results and model simulations}

Before presenting the estimation results of the interdependent model, we first carry out an independent estimation of the ACD part of the model, in order to test the empirical applicability and robustness of the ACD-GMM estimation method proposed in section 3 . Table 2 contains a comparison of the results of a GMM and a ML estimation of an $\operatorname{ACD}(1,2)$ model. The latter is based on the likelihood function of a Weibull-ACD model.

insert table 2 about here

An $\operatorname{ACD}(1,2)$ specification is selected on the basis of likelihood-ratio test, AIC and BIC. Comparing parameter estimates and their standard errors reported in table 2, it becomes evident that the GMM and ML results barely differ, that their values are approximately equal to those found in other empirical applications of ACD models, and that the standard errors are acceptably small. The unconditional expected duration implied by the GMM (ML) estimates is 1.001 (1.007), which is an almost perfect result, because the values are very close to one. ${ }^{14}$ Computation of the Ljung-Box test statistic for the estimated series $\left\{\tilde{x}_{i} \hat{\Psi}_{i}^{-1}\right\}_{1}^{T}$, assumed to be independent for ML and uncorrelated for GMM estimation, also yields positive results. The white noise null hypothesis is rejected at neither of the lags at which the Ljung-Box statistic is computed. The results confirm the Monte Carlo evidence reported in section 3.4, indicating that the ACD-GMM procedure provides a useful alternative for the estimation of the Autoregressive Conditional Duration model.

insert table 3 about here

Table 3 contains the GMM estimation results for the interdependent duration-volatility model in equations [11] and [12]. ${ }^{15}$ The parameter estimates reported in table 3 are not untypical

14 Recall the construction of diurnally adjusted durations in section 2.2.

15 After computing initial parameter estimates - using the unity matrix as a weight in the optimization - two successive runs of the GMM procedure were carried out, involving a minimization of the GMM objective function using the updated estimate of the optimal weighting matrix The convergence of the minimization 
compared to those found in estimations of GARCH models using high frequency financial data. The standard errors are acceptably small, and the sum $\hat{\alpha}_{h}+\hat{\beta}_{h}$ is clearly smaller than one, i.e. the normal duration GARCH process is far away from being an I-GARCH. The lag order chosen for the duration part of the model is the same as in the independent ACD-GMM estimation. The parameter estimates $\hat{\alpha}_{\mathrm{d}, 1}, \hat{\alpha}_{\mathrm{d}, 2}$, and $\hat{\beta}_{\mathrm{d}, 1}$ do not change very much compared to the results reported in table 2 and their standard errors remain small. The implied unconditional squared return forecast is 4.27 , and the unconditional duration is $1.02{ }^{16}$. The latter acceptably close to one. The significance level of Hansens $\chi^{2}$ test of the overidentifying restrictions is $27.9 \%$.

In the context of our paper, the sign and significance of the parameter estimates $\zeta_{1}$ and $\zeta_{2}$ are of key interest, allowing for the first time an empirical assessment of the impact of volatility indicators on the inter-transaction duration process. The statistically significant and positive parameter estimates $\hat{\zeta}_{1}$ and $\hat{\zeta}_{2}$ imply that both an increase of the expected volatility component - the best linear predictor for squared returns, $h_{i}$ - and the unexpected volatility component - the volatility shock $r_{i}^{2} h_{i}^{-1}$ - lengthen expected inter-transaction durations. In section 2.1 we have argued that this result can be interpreted as an indirect support for the hypothesis that volatility is caused by private information that affects prices when informed investors trade. If this hypothesis is true, and non-informed market participants perceived volatility as an indicator for informed trading, then the empirical result that expected and unexpected volatility indicators causes a prolongation of the expected inter-transaction duration is a logical consequence. Analyzing the economic importance of the expected and unexpected volatility component it is evident that - because of the size of the estimated parameters $\hat{\zeta}_{1}, \hat{\zeta}_{2}$ and the GARCH-parameter $\hat{\alpha}_{h}$ - it is the effect of the volatility shock (the unexpected component), which is the main driver behind the prolongation of expected intertransaction durations. Although a volatility shock will also cause an increase of the expected volatility component, $\mathrm{h}_{\mathrm{i}+1}$, the duration prolonging effect is clearly weaker than the initial effect of the volatility shock on expected durations. However, the positive parameter $\zeta_{1}$ implies that the effect of a volatility shock persists longer in the conditional expected duration process.

insert figure 8 about here

algorithm is, though computer intensive, numerically stable and acceptably fast on a well equipped UNIX workstation. [12]. $\mathrm{h}_{\mathrm{i}+\mathrm{k}}$ and $\psi_{\mathrm{i}+\mathrm{k}}, \mathrm{k}>1$, are used to replace future $\mathrm{r}_{\mathrm{i}+\mathrm{k}}^{2}$ and $\tilde{\mathrm{x}}_{\mathrm{i}+\mathrm{k}}$. 
To illustrate that the effect of a volatility shock on expected inter-transaction durations is significant not only from a statistical, but also from an economic point of view, we carry out the following sensitivity analysis. Figure 8 shows graphically the effect of a simulated volatility shock on the series $h_{i}$ and $\psi_{\mathrm{i}}$. The simulation is based on the parameter estimation results in table 3 . Before the shock at transaction number 50 , the best linear predictor $h_{i}$ is equal to 5.15 and the conditional expected duration (diurnally adjusted) is equal to 0.89 . The last simulated squared return is 0.95 and the two recent inter-transaction durations 0.28 and 0.04. In this situation, a volatility shock is introduced by a squared inter-transaction return equal to $100(\mathrm{DEM} / 100)^{2}$. This is a rare, but not an unlikely event in our Telekom study. According to the definition above this translates into a volatility shock (squared return divided by conditional variance) of 19.4. After the shock, the best linear predictor $h_{i}$ increases to 14.50, and the conditional expected duration goes up to 1.26. Assuming the diurnal factor to be equal to three minutes, this translates into an increase in the expected duration of about 65 seconds after the shock, certainly an economically significant period of time. The last intertransaction duration before the volatility shock was 0.5 , hence it is not a large lagged duration that causes this increase.

\section{insert figure 9 about here}

Figure 9 shows the persistence of a volatility shock in the conditional volatility and duration processes. Starting from a situation in which the best linear predictor $h_{i}$ and the last squared return are equal to the unconditional squared return forecast (4.27), and the conditional expected duration and the two previous durations are equal to the unconditional mean (1.02), a volatility shock is introduced - again, a squared return of $100(\mathrm{DEM} / 100)^{2}$. A forward solution of the simultaneous difference equation system [11] and [12] produces the multistep forecasts depicted in figure 9. It turns out that the persistence of a volatility shock is even higher in the conditional expected duration process: The half life of the volatility shock is 11 transactions for the conditional expected duration process and 9 transactions for the conditional volatility process.

\section{CONCLUDING REMARKS AND OUTLOOK}

The common feature of recently developed econometric models for financial markets intertransaction duration and volatility processes is their recursive structure: The duration between the events of interest, like transactions or quote updates, is assumed to influence the volatility process, whilst the volatility process does not feed back into the inter-transaction duration 
process. Although this recursive specification facilitates parameter estimation, it is quite restrictive from the economic point of view, because the model structure precludes empirical tests and econometric implementations of financial market microstructure models. We propose an econometric model in which the inter-transaction duration process is allowed to affect the volatility process, as in the case of the recursive approaches estimated by Engle (1996) and Ghysels and Jasiak (1998a). The innovation is the economic motivation, econometric specification and empirical application of an interdependent alternative in which (conditional) volatility indicators feed back into the inter-transaction duration process.

Although our interdependent formulation allows greater flexibility in modeling market microstructure processes in financial markets, it also involves methodological problems that need to be solved: Unlike in a recursive specification, the parameter estimation can no longer be separated into a first step estimation of the parameters of the Autoregressive Conditional Duration model in order to obtain a conditional expected durations series that can be used for the estimation of a GARCH model for irregularly spaced data in the second step. In order to provide an estimation procedure which is both able to solve these problem and empirically tractable, we first propose a new Generalized Method of Moments estimation procedure for Engle and Russel's (1998) Autoregressive Conditional Duration model. The GMM procedure is extended to the simultaneous GMM estimation of the interdependent duration-volatility model. A Monte Carlo study is provided to assess the performance of the GMM procedure. Applying the model to the data of an initial public offering of a European telecommunication company, we provide an indirect test of the hypothesis that volatility is caused by private information that affects the price process when informed investors trade. The empirical result that volatility shocks significantly increase expected inter-transaction durations supports this hypothesis.

The model proposed in this paper allows to address a variety of frequently discussed issues: It seems especially interesting to study the influence of different research efforts by stock market analysts: Does the result that volatility shocks increase expected inter-transaction durations also hold for standard blue chip securities which are subject to intensive research, and is the result different for less frequently traded, less intensively analyzed stocks? It is also planned to apply the model to parallel (non-anonymous) floor and (anonymous) screen trading processes. Because adverse selection costs are assumed to be lower in floor trading, where you know your counterpart, compared to screen trading, where you cannot identify whom you are trading with, we would expect significant differences of the volatility effects on expected durations. 
The following definitions of Autoregressive Conditional Duration processes correspond to Drost and Nijman's (1993) GARCH definitions. Let $\left\{\tilde{\mathrm{x}}_{\mathrm{i}}, \mathrm{i} \in \mathrm{Z}\right\}$ be a sequence of stationary durations normalized such that $E\left(\tilde{x}_{i}\right)=1$. Define operators $A(L)=1+\sum_{j}^{q} \alpha_{d, j} L^{j}$ and $B(L)=1-\sum_{j}^{\mathrm{p}} \beta_{\mathrm{d}, \mathrm{j}} \mathrm{L}^{\mathrm{j}}$ and let the sequence $\left\{\psi_{\mathrm{i}}, \mathrm{i} \in \mathrm{Z}\right\}$ be defined as the stationary solution of

$$
\mathrm{B}(\mathrm{L}) \psi_{\mathrm{i}}=\omega_{\mathrm{d}}+\{\mathrm{A}(\mathrm{L})-1\} \tilde{\mathrm{x}}_{\mathrm{i}}^{2}
$$

We assume that $\mathrm{A}(\mathrm{L})$ and $\mathrm{B}(\mathrm{L})+1-\mathrm{A}(\mathrm{L})$ have roots outside the unit circle and hence are invertible.

Definiton 1 (Strong ACD): The sequence $\left\{\tilde{x}_{i}, i \in Z\right\}$ is defined to be generated by a strong $\operatorname{ACD}(p, q)$ process, if $\omega_{d}, A(L)$ and $B(L)$ can be chosen such that

$$
\zeta_{\mathrm{i}}=\frac{\tilde{\mathrm{x}}_{\mathrm{i}}}{\psi_{\mathrm{i}}} \sim \text { i.i.d. with density } \mathrm{g}\left(\zeta_{\mathrm{i}} ; \theta_{\mathrm{g}}\right)
$$

Definition 2 (Semi-strong ACD): The sequence $\left\{\tilde{x}_{i}, i \in Z\right\}$ is defined to be generated by a semi-strong $\operatorname{ACD}(p, q)$ process, if $\omega_{d}, A(L)$ and $B(L)$ can be chosen such that

$$
\begin{aligned}
& E\left(\tilde{x}_{i} \mid \tilde{x}_{i-1}, \tilde{x}_{i-2}, \ldots . .\right)=\psi_{i} \\
& E\left(\frac{\tilde{x}_{i}}{\psi_{i}}\right)-1=0 \\
& E\left\{\left(\frac{\tilde{x}_{i}}{\psi_{i}}-1\right)\left(\frac{\tilde{x}_{i-j}}{\psi_{i-j}}-1\right)\right\}=0 \text { for } j=1,2, \ldots . .
\end{aligned}
$$

Definition 3 (Weak ACD): The sequence $\left\{\tilde{x}_{i}, i \in Z\right\}$ is defined to be generated by a weak $\operatorname{ACD}(p, q)$ process, if $\omega_{d}, A(L)$ and $B(L)$ can be chosen such that

$$
\mathrm{P}\left(\tilde{\mathrm{x}}_{\mathrm{i}} \mid \tilde{\mathrm{x}}_{\mathrm{i}-1}, \tilde{\mathrm{x}}_{\mathrm{i}-2}, \ldots \ldots\right)=\psi_{\mathrm{i}}
$$

where $\mathrm{P}\left(\tilde{\mathrm{x}}_{\mathrm{i}} \mid \tilde{\mathrm{x}}_{\mathrm{i}-1}, \tilde{\mathrm{x}}_{\mathrm{i}-2}, \ldots \ldots.\right)=\psi_{\mathrm{i}}$ denotes the best linear predictor of $\tilde{\mathrm{x}}_{\mathrm{i}}$ in terms of $1, \tilde{x}_{i-1}, \tilde{x}_{i-2}, \tilde{x}_{i-2}, \ldots .$. i.e.,

$$
E\left\{\tilde{x}_{i}-P\left(\tilde{x}_{i} \mid \tilde{x}_{i-1}, \tilde{x}_{i-2}, \ldots\right)\right\} \tilde{x}_{i-n}^{1}=0 \text { for } \mathrm{i} \geq 1 \text { and } 1=0,1 \text {, }
$$




$$
\begin{aligned}
& \mathrm{E}\left(\frac{\tilde{\mathrm{x}}_{\mathrm{i}}}{\psi_{\mathrm{i}}}\right)-1=0, \\
& \mathrm{E}\left\{\left(\frac{\tilde{\mathrm{x}}_{\mathrm{i}}}{\psi_{\mathrm{i}}}-1\right)\left(\frac{\tilde{\mathrm{x}}_{\mathrm{i}-\mathrm{j}}}{\psi_{\mathrm{i}-\mathrm{j}}}-1\right)\right\}=0 \text { for } \mathrm{j}=1,2, \ldots \ldots
\end{aligned}
$$

\section{APPENDIX A-2}

\section{DISCRETE TIME GARCH AGGREGATION}

Theorem A.1 [Drost and Werker (1996), p. 47-48]:

Let $\mathrm{h}>0$ and suppose $\left\{\mathrm{y}_{(\mathrm{h}) \mathrm{t}}, \mathrm{t} \in \mathrm{hN}\right\}$ is a weak GARCH process with parameter $\theta_{h}=\left(\Phi_{h}, \alpha_{h}, \beta_{h}, \kappa_{h}\right)$, where $\kappa_{h}$ is the kurtosis of $y_{(h) t}$. Then, for each integer $m \geq 1$ the process $\left\{\mathrm{y}_{(\mathrm{mh}) \mathrm{t}}^{(\mathrm{m})}=\sum_{\mathrm{i}=1}^{\mathrm{m}-1} \mathrm{y}_{(\mathrm{h}) \mathrm{t}+\mathrm{ih}}, \mathrm{t} \in \mathrm{mhN}\right\}$ is symmetric weak GARCH with parameter $\theta_{\mathrm{mh}}=\left(\varpi_{\mathrm{mh}}, \alpha_{\mathrm{mh}}, \beta_{\mathrm{mh}}, \kappa_{\mathrm{mh}}\right)$ (with $\left.\left|\beta_{\mathrm{mh}}\right|<1\right)$

$$
\begin{aligned}
& \varpi_{\mathrm{hm}}=\varpi_{\mathrm{DN}}\left(\mathrm{m}, \theta_{\mathrm{h}}\right)=\mathrm{m} \omega_{\mathrm{h}} \frac{1-\left(\alpha_{\mathrm{h}}+\beta_{\mathrm{h}}\right)^{\mathrm{m}}}{1-\left(\alpha_{\mathrm{h}}+\beta_{\mathrm{h}}\right)} \\
& \alpha_{\mathrm{hm}}=\alpha_{\mathrm{DN}}\left(\mathrm{m}, \theta_{\mathrm{h}}\right)=\left(\alpha_{\mathrm{h}}+\beta_{\mathrm{h}}\right)^{\mathrm{m}}-\beta_{\mathrm{h}}
\end{aligned}
$$

$\beta_{\mathrm{hm}}=\beta_{\mathrm{DN}}\left(\mathrm{m}, \theta_{\mathrm{h}}\right)$ is the real solution of

$$
\begin{gathered}
\frac{\beta_{h m}}{1+\beta_{h m}^{2}}=\frac{a\left(\alpha_{h}, \beta_{h}, \kappa_{h}, m\right)\left(\alpha_{h}+\beta_{h}\right)^{m}-b\left(\alpha_{h}, \beta_{h}, m\right)}{a\left(\alpha_{h}, \beta_{h}, \kappa_{h}, m\right)\left\{1+\left(\alpha_{h}+\beta_{h}\right)^{2 m}\right\}-2 b\left(\alpha_{h}, \beta_{h}, m\right)} \\
a\left(\alpha_{h}, \beta_{h}, \kappa_{h}, m\right)=m\left(1-\beta_{h}\right)^{2}+2 m(m-1) \frac{\left(1-\alpha_{h}-\beta_{h}\right)^{2}\left\{1-\left(\alpha_{h}+\beta_{h}\right)^{2}+\alpha_{h}^{2}\right\}}{\left(\kappa_{h}-1\right)\left\{1-\left(\alpha_{h}+\beta_{h}\right)^{2}\right\}} \\
+4 \frac{\left.\left\{m\left(1-\alpha_{h}-\beta_{h}\right)-1+\left(\alpha_{h}+\beta_{h}\right)^{m}\right\} \alpha_{h}\left(1-\left(\alpha_{h}+\beta_{h}\right)^{2}\right)+\alpha_{h}^{2}\left(\alpha_{h}+\beta_{h}\right)\right\}}{1-\left(\alpha_{h}+\beta_{h}\right)^{2}}
\end{gathered}
$$

$$
b\left(\theta_{h}, m\right)=\left\{\alpha_{h}\left(1-\left(\alpha_{h}+\beta_{h}\right)^{2}\right)+\alpha_{h}^{2}\left(\alpha_{h}+\beta_{h}\right)\right\} \frac{1-\left(\alpha_{h}+\beta_{h}\right)^{2 m}}{1-\left(\alpha_{h}+\beta_{h}\right)^{2}}
$$




$$
\begin{aligned}
\kappa_{\mathrm{hm}}= & 3+\frac{\kappa_{\mathrm{h}}-3}{\mathrm{~m}}+6\left(\kappa_{\mathrm{h}}-1\right) \times \\
& \frac{\left\{\mathrm{m}\left(1-\alpha_{\mathrm{h}}-\beta_{\mathrm{h}}\right)-1+\left(\alpha_{\mathrm{h}}+\beta_{\mathrm{h}}\right)^{\mathrm{m}}\right\}\left\{\alpha_{\mathrm{h}}\left(1-\left(\alpha_{\mathrm{h}}+\beta_{\mathrm{h}}\right)^{2}\right)+\alpha_{\mathrm{h}}^{2}\left(\alpha_{\mathrm{h}}+\beta_{\mathrm{h}}\right)\right\}}{\mathrm{m}^{2}\left(1-\alpha_{\mathrm{h}}-\beta_{\mathrm{h}}\right)^{2}\left\{1-\left(\alpha_{\mathrm{h}}+\beta_{\mathrm{h}}\right)^{2}+\alpha_{\mathrm{h}}^{2}\right\}}
\end{aligned}
$$

Let $\theta_{\mathrm{DN}}$ be the transfer function corresponding to Theorem A.1 that transforms highfrequency parameters into low frequency ones, i.e. $\theta_{\mathrm{DN}}\left(\mathrm{m}, \theta_{\mathrm{h}}\right)=\theta_{\mathrm{mh}}$. The interpretation of theorem A.1 implies $\theta_{\mathrm{DN}}\left[\theta_{\mathrm{DN}}\left(\mathrm{m}, \theta_{\mathrm{h}}\right), \mathrm{n}\right]=\theta_{\mathrm{DN}}\left(\mathrm{mn}, \theta_{\mathrm{h}}\right)$. Drost and Werker (1996) argue that the latter equality holds true if the integers $m$ and $n$ are replaced by arbitrary reals. If a weak GARCH process with parameter $\theta_{\mathrm{h}}$ is known to be the aggregate over $\mathrm{m}$ periods of some other higher frequency GARCH process, then the parameter of the latter high-frequency process is given by $\theta_{\mathrm{h} / \mathrm{m}}=\theta_{\mathrm{DN}}\left(\theta_{\mathrm{h}}, 1 / \mathrm{m}\right)$. If one assumes that the observed process at frequency, say, $\mathrm{g}$ is infinitely divisible, i.e. if one assumes that for each integer $\mathrm{m}$ there exists an underlying high frequency GARCH process such that the observed process is the sum over $\mathrm{m}$ periods of the high-frequency process, then the transfer function $\mathrm{q}$ determines the parameters by $\theta_{\mathrm{h}}=\theta_{\mathrm{DN}}\left(\theta_{\mathrm{g}}, \mathrm{h} / \mathrm{g}\right)$.

\section{APPENDIX A-3}

\section{ALGORITHM TO CONSOLIDATE IBIS SPLIT TRANSACTIONS}

We consolidate IBIS split transactions according to the following rules: If we observe two successive transactions with a transaction duration of less than one second, these two transactions are recognized as being part of a split transaction. If the time between the second and third transactions is also within one second, an additional condition must be satisfied before it can be counted as a sub-transaction of a split transaction: The sequence of transaction prices for the three transactions to be considered must be either non increasing or non decreasing. Non-increasing prices would imply that a trader has initiated a split transaction on the bid side of the order book, i. e. sold to the bid side with falling (or constant) transaction prices in the sub-transactions. Non-decreasing prices would imply that a trader has initiated a split transaction on the ask side of the order book and bought increasingly more expensive (or price constant) asks. The consolidation stops if either the duration between two successive transactions is no longer less than one second or the condition of non increasing (non decreasing) prices is no longer met. The time stamp of the first sub-transaction of the split transaction is then assigned to the consolidated transaction. The volume of the consolidated transaction is the sum of the volumes of the sub-transactions and the price is the 
volume weighted average of the prices of the sub-transactions. Given the new transaction definitions, transaction durations and returns are revised.

\section{REFERENCES}

Amemiya, T. and R. Y. Wu (1972), "The effect of aggregation on prediction in the autoregressive model", Journal of the American Statistical Association, 67, 628-632.

Andersen T. G. and T. Bollerslev (1997), "Intraday periodicity and volatility persistence in financial markets “, Journal of Empirical Finance, Vol. 4, No. 2-3, 115-158.

Andersen T. G. and T. Bollerslev (1998), "Answering the sceptics: Yes, standard volatility models do provide accurate forecasts", in: High frequency data in finance II. Proceedings, Olsen and Associates, Zurich Switzerland.

Andrews, D. W. K. (1991), "Heteroskedasticity and autocorrelation consistent covariance matrix estimation", Econometrica, Vol. 59, 817-858.

Andrews, D. W. K. and C. Monahan (1992), "An improved heteroskedasticity and autocorrelation consistent covariance matrix estimator", Econometrica, Vol. 60. 953-966.

Barclay, M.J., Litzenberger, R.H. and J. B. Warner (1990), "Private information, trading Volume, and stockreturn variances", Review of Financial Studies, Vol. 3, 233-253.

Bates, C. and H. White (1988), "Efficient instrumental variables estimation of systems of implicit heterogeneous nonlinear dynamic equations with nonspherical errors, in W.A. Barnett, E.R. Berndt and H. White (eds.) "Dynamic econometric modelling" Cambridge University Press.

Bauwens, L. and P. Giot (1998a), "Asymmetric ACD models: Introducing price information in ACD Models with a two state transition model", CORE Discussion paper 9844.

Bauwens, L. and P. Giot (1998b), "The logarithmic ACD Model: An application to market microstructure and NASDAQ", CORE Discussion paper 9789 (Revised Version).

Bisière, C. and T. Kamionka (1998), "Timing of orders, orders aggressivness and the order book in the Paris Bourse", paper presented at the 53 th ESEM conference, Berlin.

Bollerslev, T. (1986), "Generalized autoregressive conditional heteroskedasticity", Journal of Econometrics, 31, 307-327.

Bollerslev, T., Chou, R.Y, and K.F. Kroner (1992), "ARCH modeling in finance. A review of the theory and empirical evidence", Journal of Econometrics 52, 5-29.

Buse, A. and L. Lim (1977), "Cubic splines as a special case of Restricted Least Squares", Journal of the American Statistical Association, Vol. 72, No. 72, 64-68.

Campbell, J., A. Lo and A.C. MacKinlay (1997), The econometrics of financial markets Princeton University Press.

Coppejans M. and I. Domowitz (1998), "Stock and flow as inputs to limit order book trading activity", working paper, Pennsylvania State University.

Covrig, V. and M. T. Melvin (1998), "Asymmetric information and price discovery in the FX market: Does Tokyo know more about the yen?", in: High frequency data in finance II. Proceedings, Olsen and Associates, Zurich Switzerland.

Deutsche Börse AG (1995), "Integrated Stock Exchange Trading and Information System- IBIS”, Frankfurt.

Diamond, D. W. and R. E. Verrecchia (1987), " Constraints on short-selling and asset price adjustments to private information", Journal of Financial Economics, 18, 227-311.

Diebold, F.X. (1988), Empirical modeling of exchange rates. Springer .

Drost, F. C. and B. J. M. Werker (1996), "Closing the GARCH gap: Continuous time GARCH modeling", Journal of Econometrics 74 31-57.

Drost, F. C. and T. E. Nijman (1993), "Temporal aggregation of GARCH Processes", Econometrica, Vol. 61, No. 4 (July, 1993), 907-927. 
Easley, D., N. Kiefer, M. O’Hara and J.P. Paperman (1996), “Liquidity, information, and infrequently traded stocks", Journal of Finance, 51, 1405-1436.

Engle, R. F. (1982), “Autoregressive Conditional Heteroskedasticity with estimates of the variance of United Kingdom inflation”, Econometrica Vol. 50, 987-1007.

Engle, R. F. (1996), "The econometrics of ultra-high frequency data”, discussion paper 96-15, University of California, San Diego.

Engle, R. F. and J. R. Russell (1995b), "Forecasting the frequency of changes in quoted foreign exchange prices with the autoregressive conditional duration model“", discussion paper 95-33, University of California, San Diego.

Engle, R. F. and J. R. Russell (1997), "Forecasting the frequency of changes in quoted foreign exchange prices with the autoregressive conditional duration model“, Journal of Empirical Finance 4, 187-212.

Engle, R. F. and J. R. Russell (1994), "Forecasting transaction rates: The Autoregressive Conditional Duration model”, Discussion Paper 94-27, University of California, San Diego.

Engle, R. F. and J. R. Russell (1995a), "Autoregressive conditional duration: A new model for irregularly spaced time series data", discussion paper 94-27R, University of California, San Diego.

Engle, R. F. and J. R. Russell (1998a), "Econometric analysis of discrete-valued, irregularly-spaced financial transactions data using a new autoregressive conditional multinomial model", in: High frequency data in finance II. Proceedings, Olsen and Associates, Zurich Switzerland.

Engle, R.F. and J.R. Russell (1998b), “Autoregressive Conditional Duration: A new model for irregularly spaced transaction data”, Econometrica, Vol. 66, No. 5, 1127-1162.

French, K. and R. Roll (1986), "Stock return variances: The arrival of information and the reaction of traders", Journal of Financial Economics, 17, 5-26.

Gallant, A. R. (1987), Nonlinear statistical models. Wiley.

Gerhard, F., D. Hess, W. Pohlmeier (1998), “Analyzing the market microstructure of intraday LIFFE Bund futures trading", in: High frequency data in finance II. Proceedings, Olsen and Associates, Zurich Switzerland.

Ghysels, E. and J. Jasiak (1998a), "GARCH for irregularly spaced financial data: The ACD-GARCH model", Studies in Nonlinear Economics and Econometrics, Vol. 2 No.4, 133-149.

Ghysels, E. and J. Jasiak (1998b), "Long term dependence in trading”, Working Paper, York University.

Ghysels, E., C. Gouriéroux, and J. Jasiak (1998), "Stochastic volatility duration models", in: High frequency data in finance II. Proceedings, Olsen and Associates, Zurich Switzerland.

Ghysels, E., A. C. Harvey, and E. Renault (1996): "Stochastic Volatility". In: Handbook of Statistic, ed. by Maddala, G. S. and C. R. Rao, Vol. 14, 119-183.

Glosten, L. and P. Milgrom (1985), "Bid, ask, and transaction prices in a specialist market with heterogeneously informed traders", Journal of Financial Economics, 71-100.

Glosten, L., R. Jagannathan, and D. Runkle (1993), "Relationship between the expected value and the volatility of the nominal excess return on stocks", Journal of Finance, 48, 1779-1801.

Gouriéroux, C. (1997): ARCH models and financial applications. Springer.

Grammig, J. and K. Maurer (1998), “A new Autoregressive Conditional Duration model”, discussion paper 55/1998 (revised version) SFB 373, Humboldt University Berlin.

Hafner, C. (1996), "Estimating high frequency foreign exchange rate volatility with nonparametric ARCH Models, discussion paper SFB 373, Humboldt University Berlin.

Hafner, C. (1998), "Durations, volume and the prediction of financial returns in transaction time -evidence from the German futures exchange", working paper, Humbold University Berlin.

Hamilton, J. D. (1994), Time series analysis, Princeton University Press.

Hansen, L. P. (1982), “Large sample properties of Generalized Method of Moments estimators", Econometrica $50,1029-1054$.

Härdle, W. (1990), Applied Nonparametric Regression, Cambridge University Press, Cambridge. 
Harvey, A. C. and R.G. Pierse (1984), "Estimating missing observations in economic time series", Journal of the American Statistical Association, 79, 125-131.

Hasbrouk, J. (1988), “Trades, quotes, inventories and information”, Journal of Finance, 46, 179-252.

Hasbrouk, J. (1991), “Measuring the information content of stock trades”, Journal of Finance, 46, 179-207.

Hausman, J., A. Lo and C. MacKinlay (1992), “An ordered probit analysis of transaction stock prices”, Journal of Financial Economics, 31, 319-379.

Hautsch, N. (1998), "Analyzing the time between trades with a gamma coumpound hazard model. An application to LIFFE bond future transactions", working paper Center of Finance and Econometrics, Konstanz University.

Keim, D. B. and R. F. Stambaugh, "A further investigation of the weekend effect in stock returns", Journal of Finance, Vol. 39, 819-834.

Lancaster, T. (1990), The econometric analysis of transition data, Cambridge University Press.

Lütkepohl, H. (1986), "Forecasting vector ARMA processes with systematically missing observations", Journal of Business and Economic Statistics, 4, 375-390.

Paolella, M. S. (1998), “Generalized GARCH models with nonnormal distributions”, working paper, Institute of Statistics and Econometrics, Kiel University.

Meddahi, N, E. Renault and B. J. M. Werker (1998), "Modelling high-frequency data in continuous time", in: High frequency data in finance II. Proceedings, Zurich, Switzerland.

Newey, W. and K.D. West (1987), “A simple, positive semi-definite, heteroskedasticity and autocorrelation consistent covariance matrix”, Econometrica Vol. 55, No. 3, 703-708.

O’Hara, M. (1995), Market microstructure theory, Basil Blackwell, Oxford.

Ogaki, M. (1993), "Generalized Method of Moments: Econometric applications”, in: G. S. Madda, C.R. Rao, H.D. Vinod (eds.): Handbook of Statistics, Vol 11, 455-488.

Pai, J. S., and W. Polasek (1995), "Irregularly spaced AR and ARCH (ISAR-ARCH) models", High frequency data in finance. Proceedings, Olsen and Associates, Zurich Switzerland.

Palm, F. C. and T. E. Nijman (1984), "Missing observations in the dynamic regression model", Econometrica, $52,1415-1435$.

Rich, R. W., J. Raymond, and J.S. Butler (1991), "Generalized instrumental variables estimation of Autoregressive Conditional Heteroskedastic models”, Economics Letters 35, 179-185.

Shepard, N.E. (1993), "Fitting nonlinear time-series models with applications to stochastic volatility models", Journal of Applied Econometrics, 8, 135-152.

Shepard, N.E. (1996), "Statistical aspects of ARCH and Stochastic Volatility", in: D.R. Cox, D. V. Hinkley and O. E. Barndorff-Nielsen (eds.): Likelihood, Time Series with Econometric and Other Applications, London.

Taylor, S. J. (1986), Modelling financial time series, John Wiley, Chichester.

West, K.D. (1997), “Another heteroskedasticity and autocorrelation consistent covariance matrix estimator", Journal of Econometrics 76, 171-191. 


\section{FIGURE 1}

Temporary Aggregation of a Symmetric Weak GARCH(1,1) Process for Flow Variables ${ }^{\mathrm{a}}$

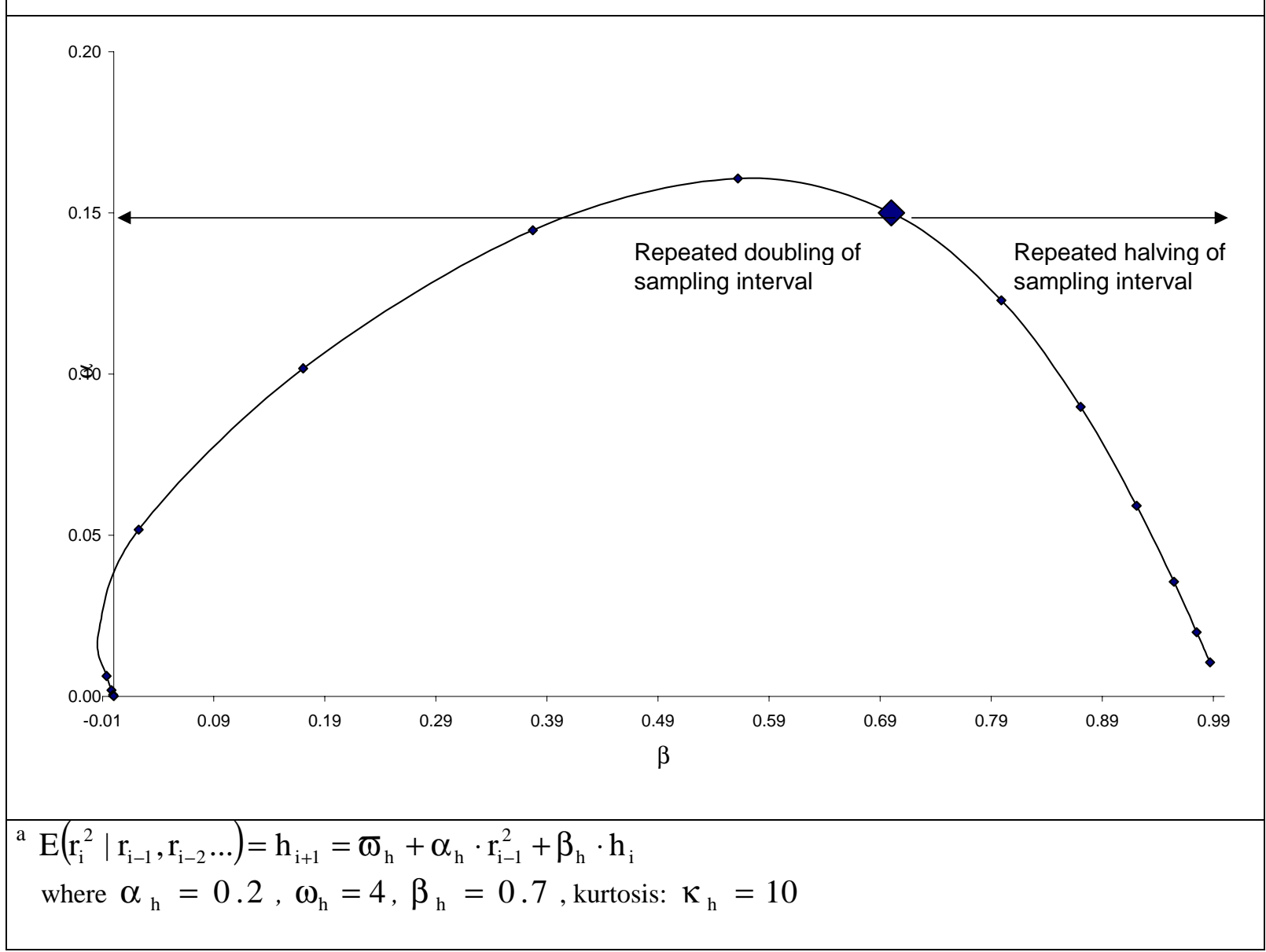




\section{FIGURE 2}

Monte Carlo Results ${ }^{\mathrm{a}}$ : DGP: Exponential-ACD $(1,1)$

$\psi_{\mathrm{i}+1}=\omega_{\mathrm{d}}+\alpha_{\mathrm{d}, 1} \tilde{\mathrm{x}}_{\mathrm{i}}+\beta_{\mathrm{d}, 1} \psi_{\mathrm{i}} ; \bar{\varpi}_{\mathrm{d}}=0.2, \alpha_{\mathrm{d}, 1}=0.1, \beta_{\mathrm{d}, 1}=0.7$
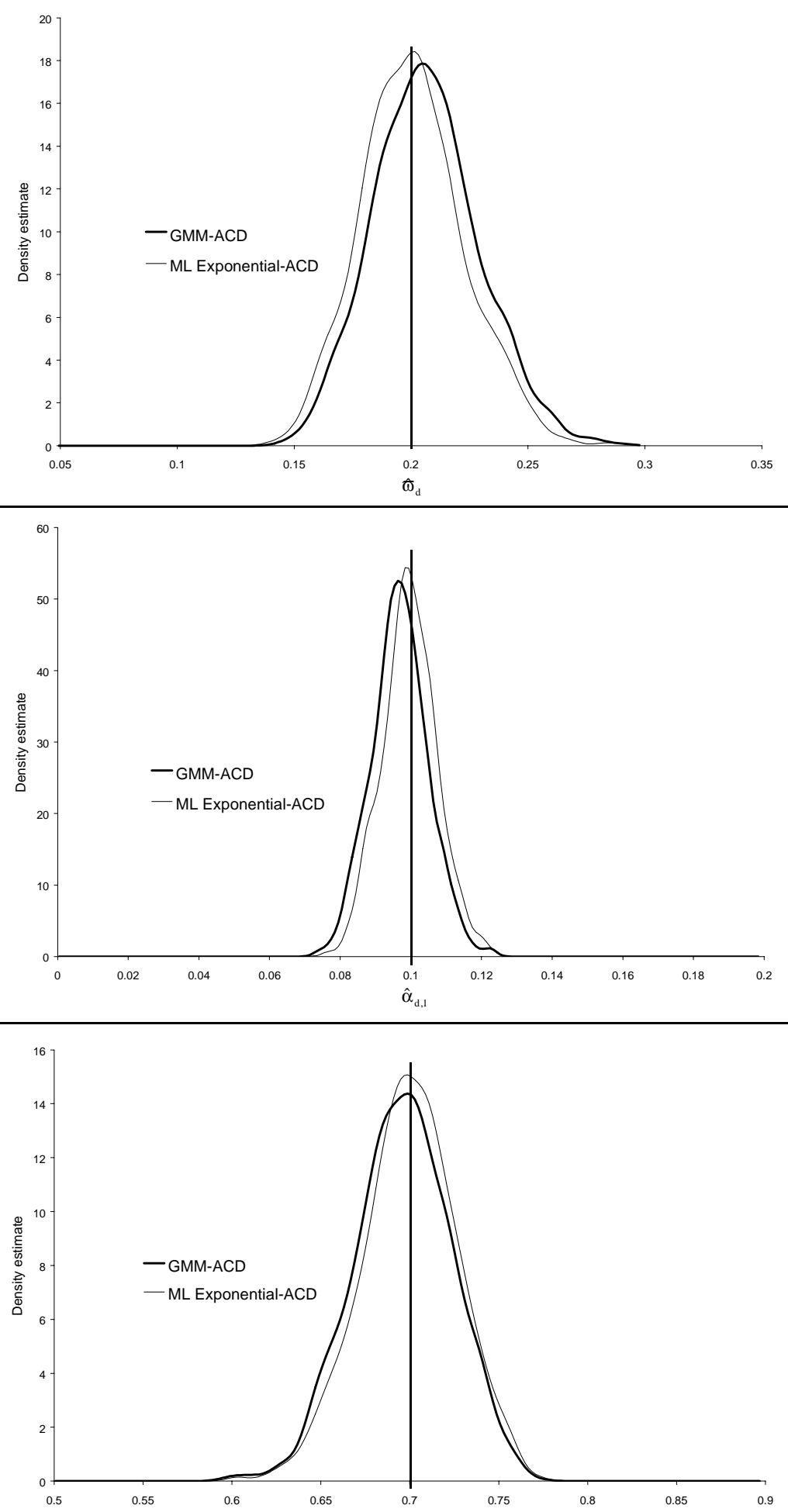

a 1000 replications, 15000 observations each.

Gaussian kernel with smoothing parameter as proposed by Silverman (1986) p. 48. 


\section{FIGURE 3}

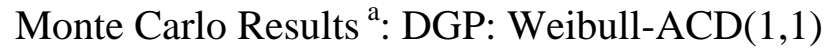

$\psi_{\mathrm{i}+1}=\omega_{\mathrm{d}}+\alpha_{\mathrm{d}, 1} \tilde{\mathrm{x}}_{\mathrm{i}}+\beta_{\mathrm{d}, 1} \psi_{\mathrm{i}} ; \bar{\omega}_{\mathrm{d}}=0.2, \alpha_{\mathrm{d}, 1}=0.1, \beta_{\mathrm{d}, 1}=0.7, \gamma=0.6$
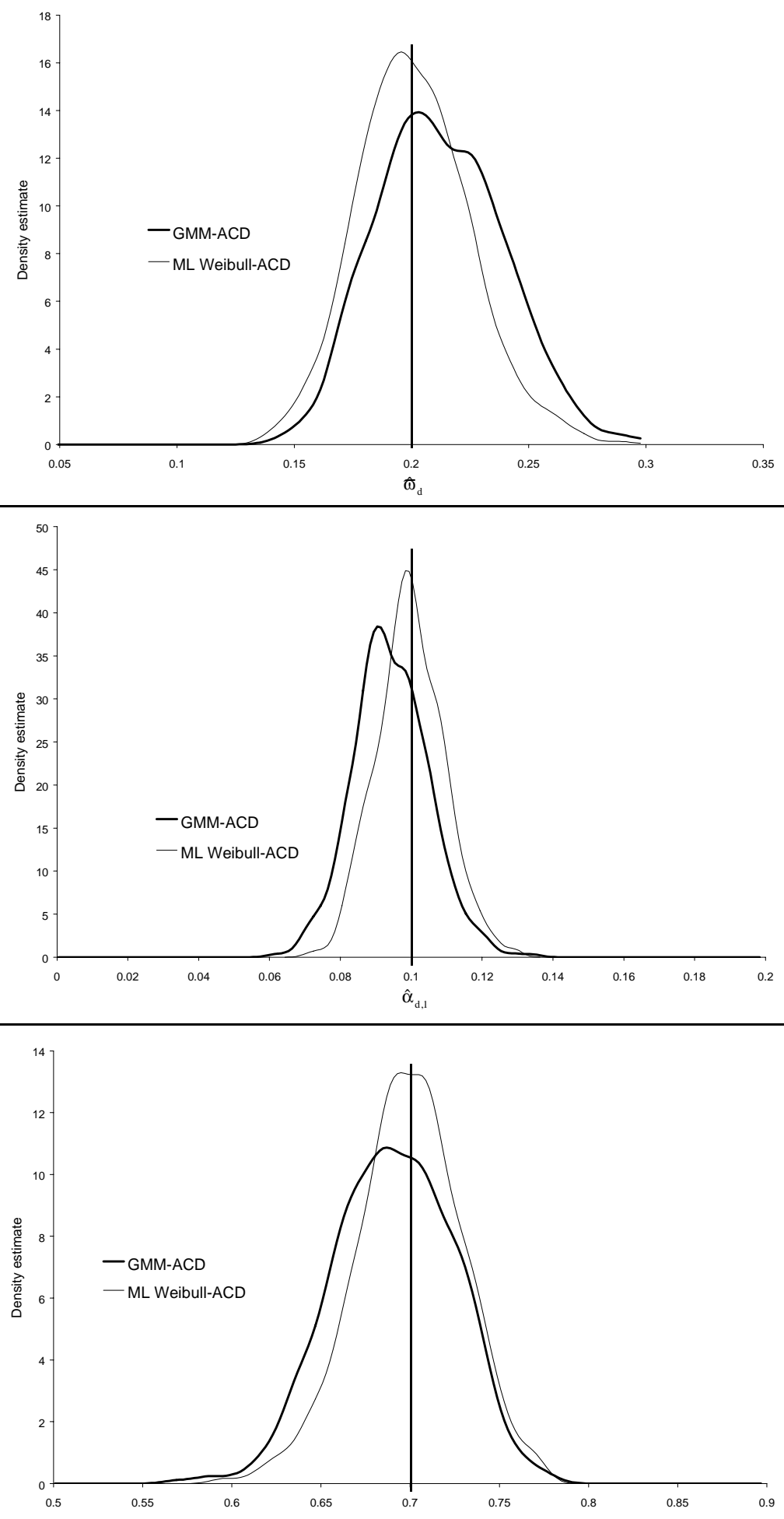

${ }^{a} 1000$ replications, 15000 observations each.

Gaussian kernel with smoothing parameter as proposed by Silverman (1986) p. 48. 
FIGURE 4

Adjusted Return Series

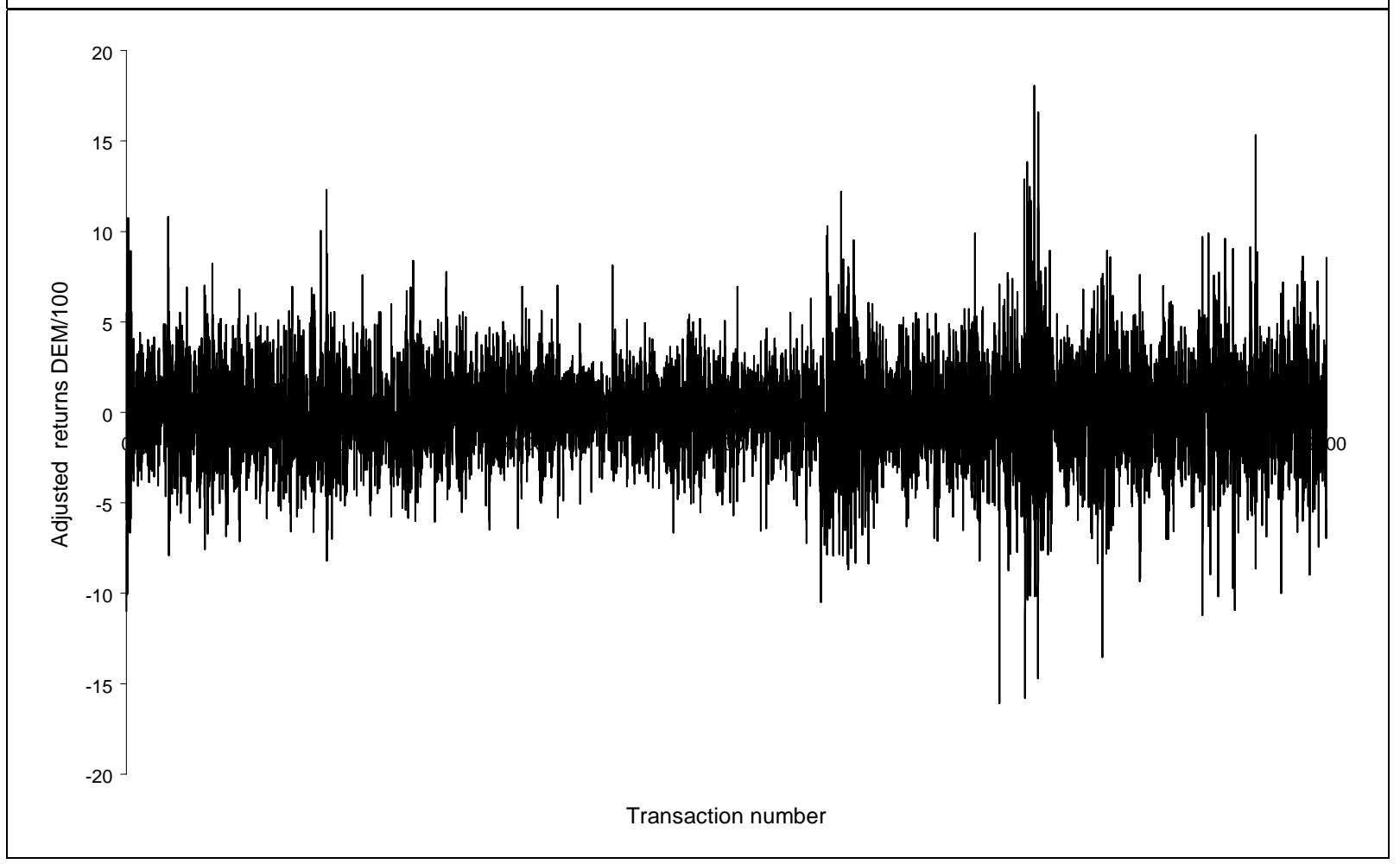

FIGURE 5

Squared Adjusted Return Series

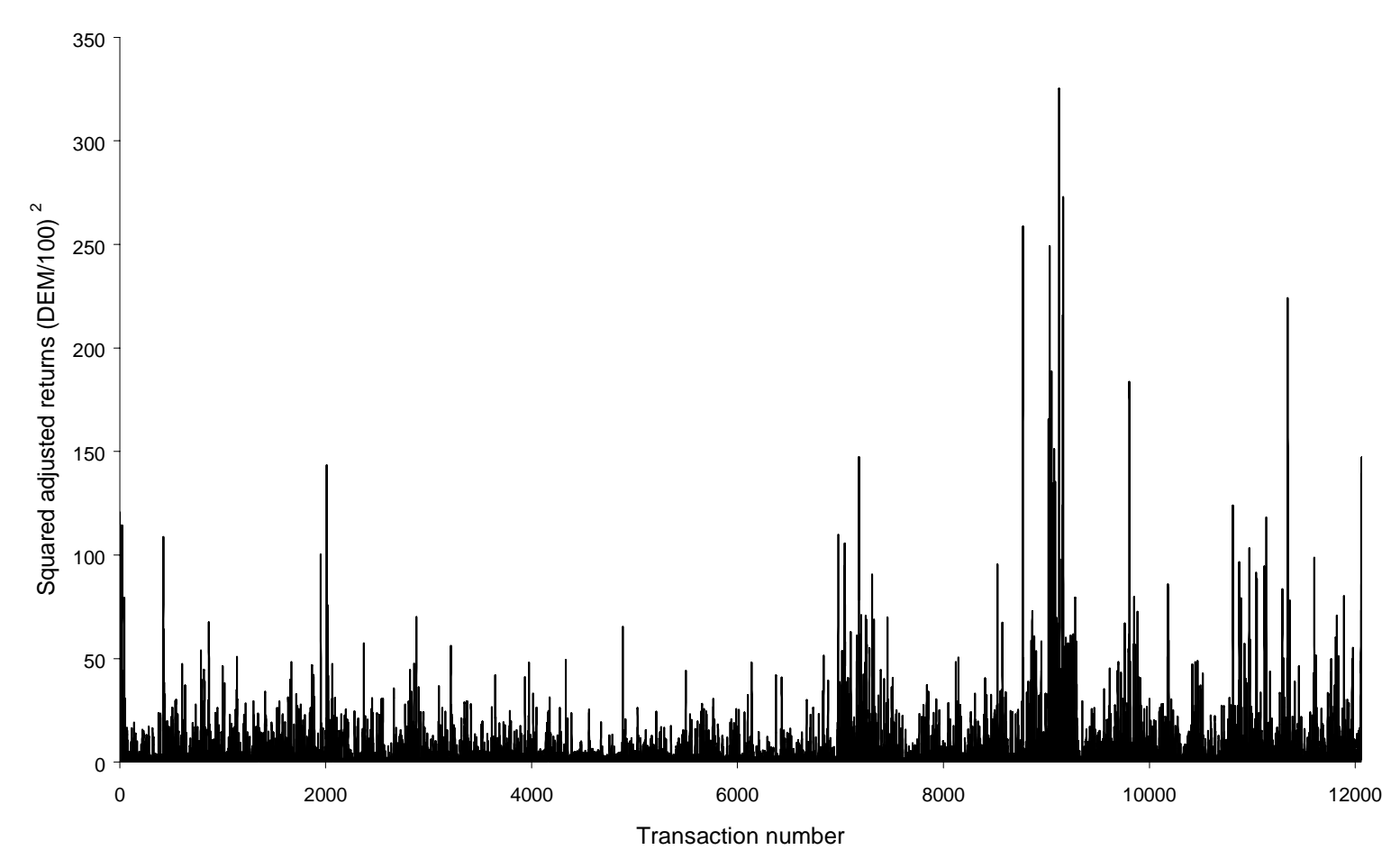




\section{FIGURE 6}

Kernel Density Estimate for Adjusted Returns ${ }^{\mathrm{a}}$

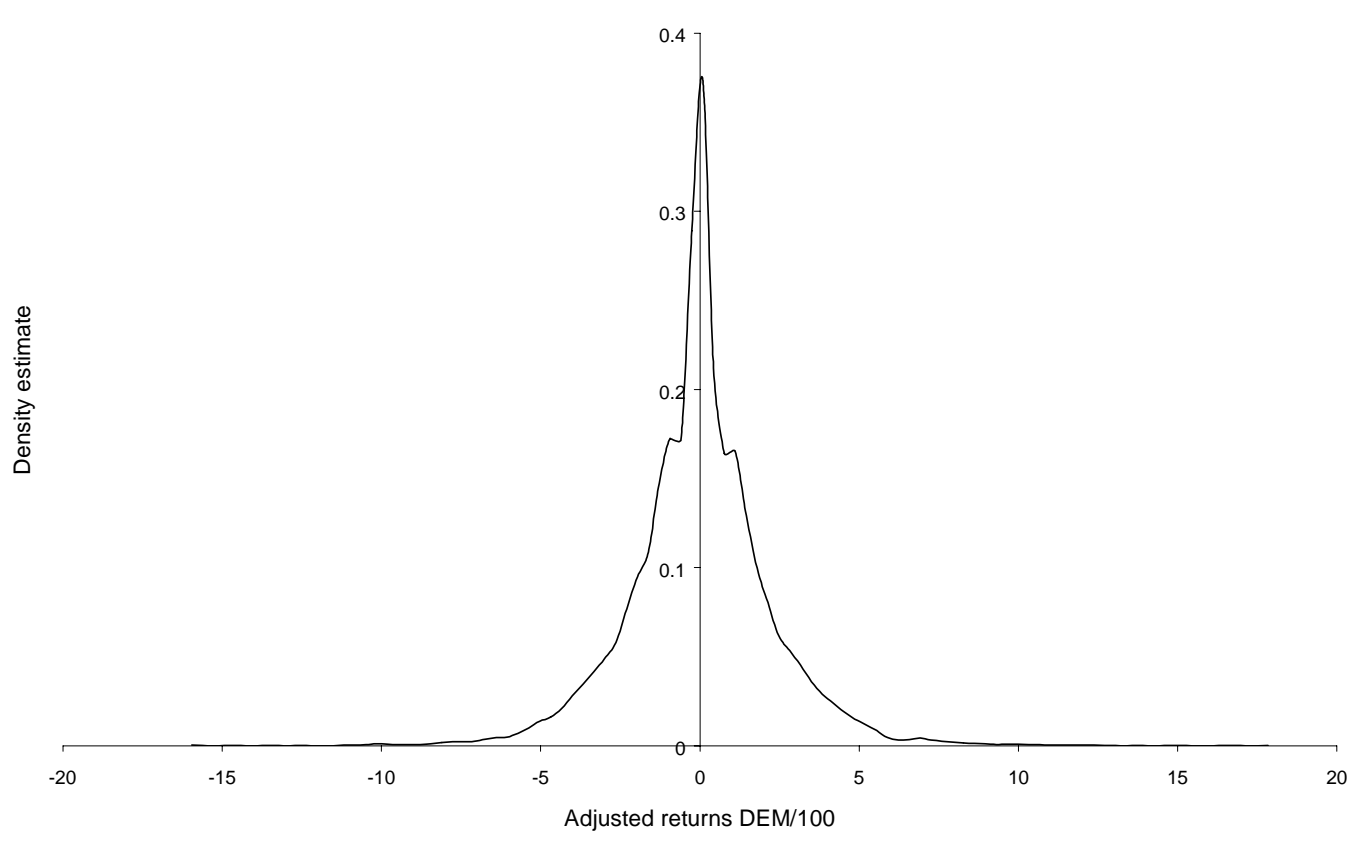

Gaussian kernel with smoothing parameter as proposed by Silverman (1986) p. 48.

FIGURE 7

Kernel Density Estimate for Diurnally Adjusted Durations ${ }^{\mathrm{a}}$

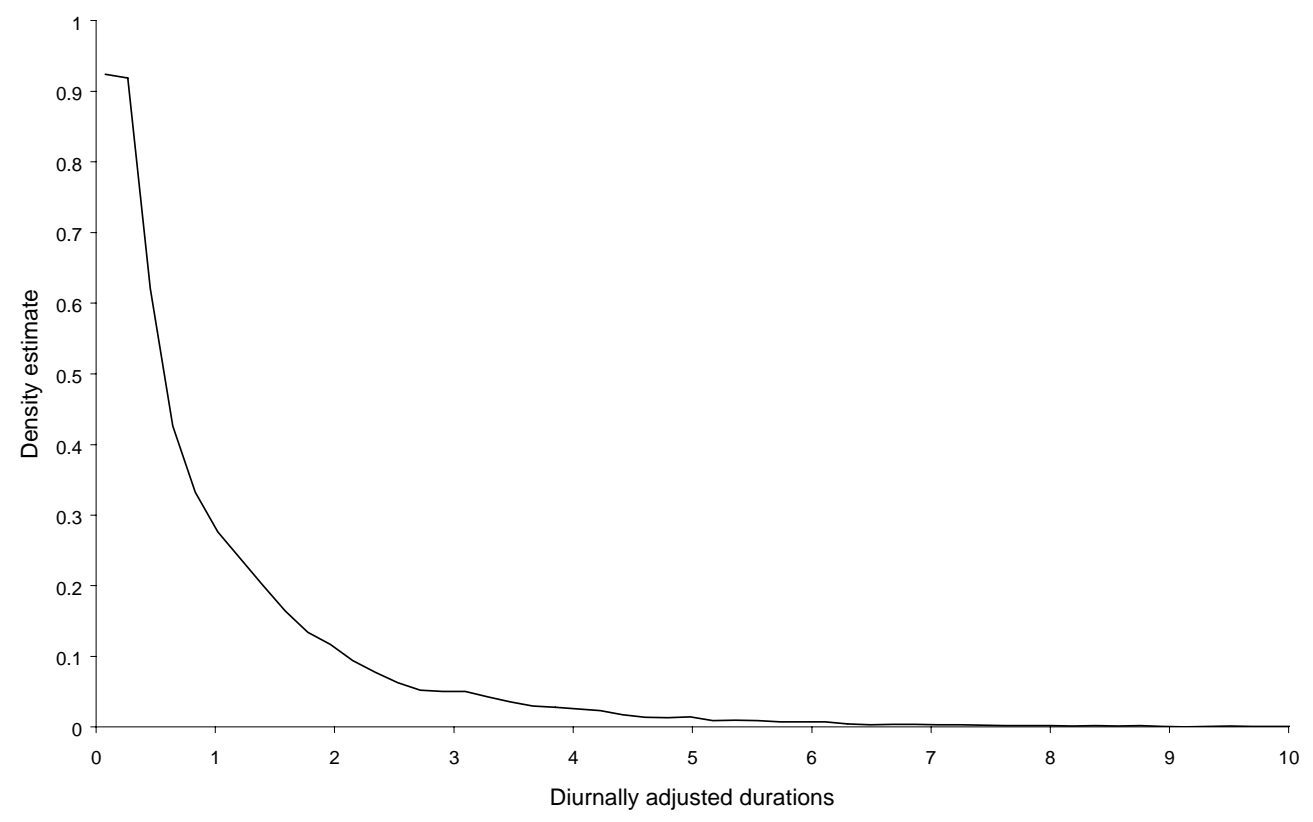

Gaussian kernel with smoothing parameter as proposed by Silverman (1986) p. 48. 


\section{FIGURE 8}

Model Simulation of a Volatility Shock

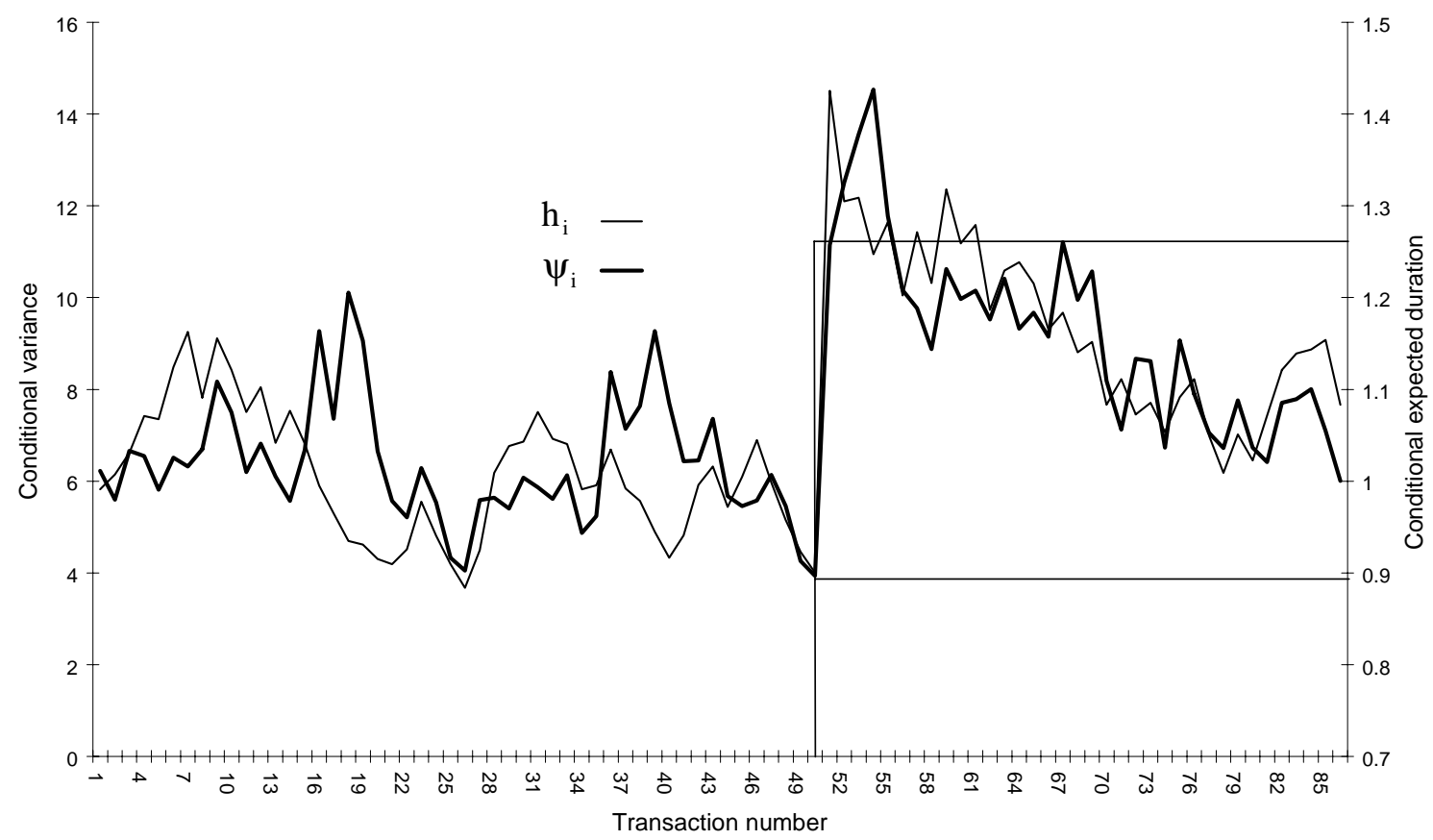

FIGURE 9

Persistence of Volatility Shock and Convergence of $\psi_{\mathrm{i}}$ and $\mathrm{h}_{\mathrm{i}}$ to Unconditional Means (Multi-Step Forecast)

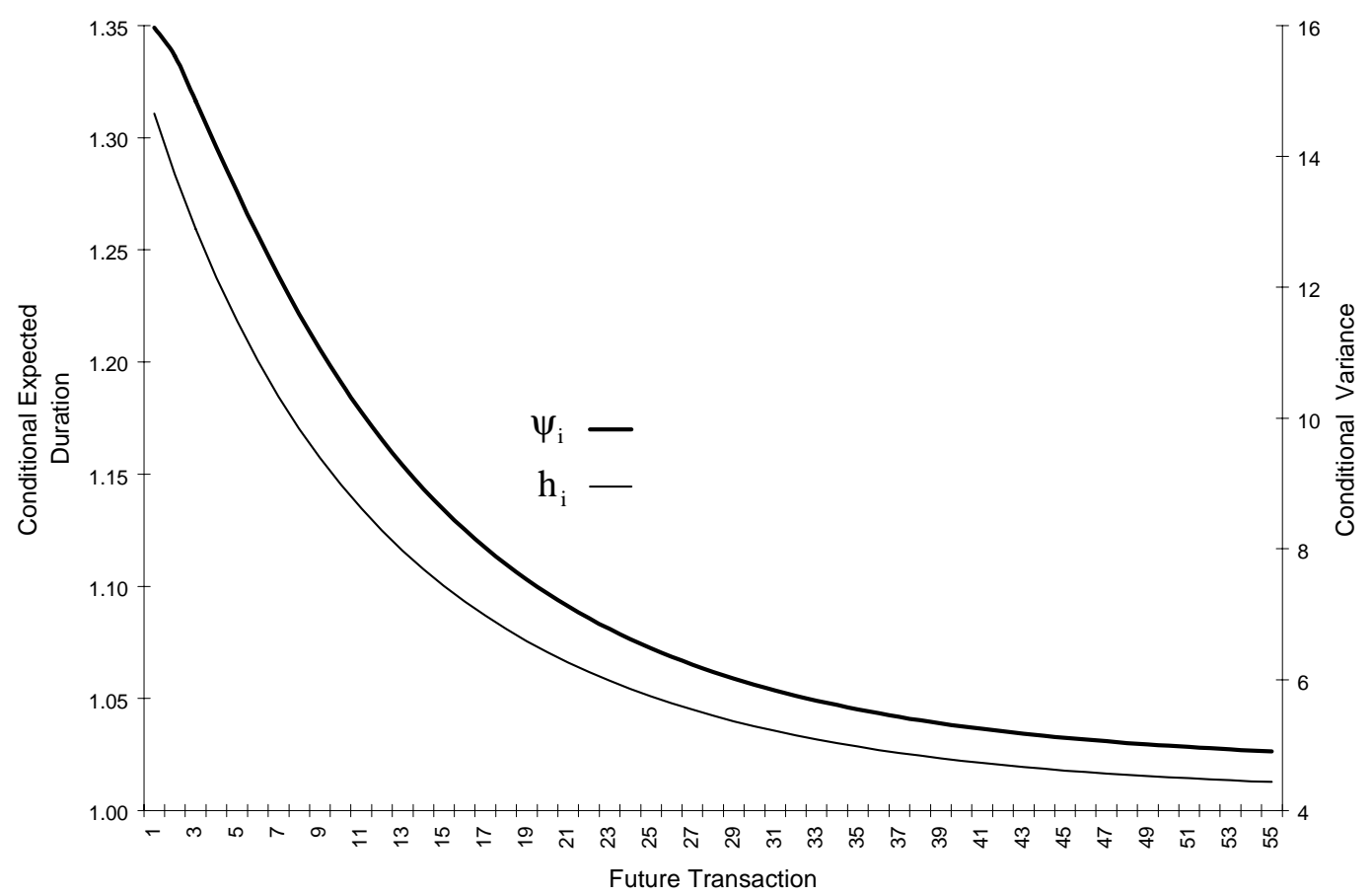


TABLE 1

Monte Carlo Results

DGP: Exponential-ACD $(1,1)$

$\psi_{\mathrm{i}+1}=\omega_{\mathrm{d}}+\alpha_{\mathrm{d}, 1} \tilde{\mathrm{x}}_{\mathrm{i}}+\beta_{\mathrm{d}, 1} \psi_{\mathrm{i}} ; \bar{\omega}_{\mathrm{d}}=0.2, \alpha_{\mathrm{d}, 1}=0.1, \beta_{\mathrm{d}, 1}=0.7$

\begin{tabular}{lcccccc}
\hline & $\begin{array}{c}\omega_{\mathrm{d}} \\
\text { GMM- } \\
\text { ACD }\end{array}$ & $\begin{array}{c}\omega_{\mathrm{d}} \\
\text { ML- } \\
\text { Exponent. } \\
\text { ACD }\end{array}$ & $\begin{array}{c}\alpha_{\mathrm{d}, 1} \\
\text { GMM- } \\
\text { ACD }\end{array}$ & $\begin{array}{c}\alpha_{\mathrm{d}, 1} \\
\text { ML- } \\
\text { Exponent. } \\
\text { ACD }\end{array}$ & $\begin{array}{c}\beta_{\mathrm{d}, 1} \\
\text { GMM- } \\
\text { ACD }\end{array}$ & $\begin{array}{c}\beta_{\mathrm{d}, 1} \\
\text { ML- } \\
\text { Exponent. } \\
\text { ACD }\end{array}$ \\
Root MSE & 0.024 & 0.022 & 0.009 & 0.008 & 0.028 & 0.027 \\
Mean AE & 0.018 & 0.017 & 0.007 & 0.006 & 0.022 & 0.021 \\
Median AE & 0.015 & 0.015 & 0.006 & 0.005 & 0.018 & 0.017 \\
Mean & 0.206 & 0.201 & 0.097 & 0.100 & 0.696 & 0.700 \\
Std Dev & 0.023 & 0.022 & 0.008 & 0.008 & 0.027 & 0.027 \\
10\% Qntl. & 0.179 & 0.173 & 0.086 & 0.089 & 0.660 & 0.664 \\
25\% Qntl. & 0.191 & 0.185 & 0.092 & 0.095 & 0.678 & 0.683 \\
50\% Qntl. & 0.205 & 0.200 & 0.097 & 0.099 & 0.696 & 0.700 \\
75\% Qntl. & 0.221 & 0.214 & 0.102 & 0.105 & 0.715 & 0.718 \\
90\% Qntl. & 0.237 & 0.231 & 0.107 & 0.110 & 0.731 & 0.734 \\
\hline
\end{tabular}

DGP: Weibull-ACD $(1,1)$

$\psi_{\mathrm{i}+1}=\omega_{\mathrm{d}}+\alpha_{\mathrm{d}, 1} \tilde{\mathrm{x}}_{\mathrm{i}}+\beta_{\mathrm{d}, 1} \psi_{\mathrm{i}} ; \bar{\varpi}_{\mathrm{d}}=0.2, \alpha_{\mathrm{d}, 1}=0.1, \beta_{\mathrm{d}, 1}=0.7, \gamma=0.6$

\begin{tabular}{|c|c|c|c|c|c|c|}
\hline & $\omega_{\mathrm{d}}$ & $\omega_{\mathrm{d}}$ & $\alpha_{d, 1}$ & $\alpha_{d, 1}$ & $\beta_{\mathrm{d}, 1}$ & $\beta_{\mathrm{d}, 1}$ \\
\hline & $\begin{array}{c}\text { GMM- } \\
\text { ACD }\end{array}$ & $\begin{array}{c}\text { ML- } \\
\text { Weibull } \\
\text { ACD }\end{array}$ & $\begin{array}{l}\text { GMM- } \\
\text { ACD }\end{array}$ & $\begin{array}{c}\text { ML- } \\
\text { Weibull } \\
\text { ACD }\end{array}$ & $\begin{array}{c}\text { GMM- } \\
\text { ACD }\end{array}$ & $\begin{array}{c}\text { ML- } \\
\text { Weibull } \\
\text { ACD }\end{array}$ \\
\hline Root MSE & 0.030 & 0.024 & 0.012 & 0.010 & 0.035 & 0.030 \\
\hline Mean AE & 0.024 & 0.019 & 0.010 & 0.008 & 0.028 & 0.024 \\
\hline Median AE & 0.021 & 0.016 & 0.008 & 0.006 & 0.025 & 0.019 \\
\hline Mean & 0.212 & 0.201 & 0.094 & 0.100 & 0.690 & 0.700 \\
\hline Std Dev & 0.027 & 0.024 & 0.011 & 0.010 & 0.034 & 0.030 \\
\hline $10 \%$ Qntl. & 0.178 & 0.172 & 0.081 & 0.087 & 0.647 & 0.662 \\
\hline $25 \%$ Qntl. & 0.193 & 0.184 & 0.087 & 0.094 & 0.667 & 0.682 \\
\hline $50 \%$ Qntl. & 0.210 & 0.200 & 0.094 & 0.099 & 0.690 & 0.701 \\
\hline $75 \%$ Qntl. & 0.231 & 0.216 & 0.101 & 0.106 & 0.715 & 0.721 \\
\hline $90 \%$ Qntl. & 0.248 & 0.231 & 0.108 & 0.112 & 0.734 & 0.739 \\
\hline
\end{tabular}

${ }^{a} \mathrm{R}=1000$ replications with 15000 observations each.

RMSE (Root mean square error) : $\left[\frac{1}{\mathrm{R}}\left(\sum_{\mathrm{r}=1}^{\mathrm{R}} \hat{\theta}_{\mathrm{r}}-\theta^{\circ}\right)\right]^{1 / 2}$.

Median AE (Median absolute error): median $_{\mathrm{r}}\left|\hat{\theta}_{\mathrm{r}}-\theta^{\circ}\right|$.

Mean AE (Mean absolute error): $\frac{1}{\mathrm{R}} \sum_{\mathrm{r}=1}^{\mathrm{R}}\left|\hat{\theta}_{\mathrm{r}}-\theta^{\circ}\right|$.

$\hat{\theta}_{\mathrm{r}}$ is the coefficient estimate in replication $r$ and $\theta^{0}$ is the true value. $\theta$ stands for $\omega_{\mathrm{d}}, \alpha_{\mathrm{d}, 1}, \beta_{\mathrm{d}, 1}$. 
TABLE 2

Independent ACD Estimation: $\mathrm{ML}^{\mathrm{a}}$ and $\mathrm{GMM}^{\mathrm{b}}$ Results

\begin{tabular}{lllll}
\hline & $\begin{array}{c}\text { ML } \\
\text { Estimate }\end{array}$ & $\begin{array}{c}\text { Standard } \\
\text { Error }\end{array}$ & $\begin{array}{c}\text { GMM } \\
\text { Estimate }\end{array}$ & $\begin{array}{c}\text { Standard } \\
\text { Error }\end{array}$ \\
$\bar{\sigma}_{\mathrm{d}}$ & 0.1760 & 0.027 & 0.2009 & 0.041 \\
$\alpha_{\mathrm{d}, 1}$ & 0.1182 & 0.012 & 0.0903 & 0.010 \\
$\alpha_{\mathrm{d}, 2}$ & -0.0314 & 0.014 & -0.0226 & 0.014 \\
$\beta_{\mathrm{d}, 1}$ & 0.7379 & 0.034 & 0.7316 & 0.052 \\
$\gamma$ & 0.8478 & 0.006 & & \\
\hline
\end{tabular}

Log-

likelihood $\quad-11673.3$

AIC $\quad 23356.6$

BIC 23393.6

Hansen $\quad \chi^{2}(46)=66.6$

$\chi^{2}$ test p-value: 0.025

\begin{tabular}{|c|c|c|}
\hline $\begin{array}{l}\text { Ljung-Box } \\
\text { statistic } \\
\left\{\tilde{\mathrm{x}}_{\mathrm{i}} \hat{\psi}_{\mathrm{i}}^{-1}\right\}_{1}^{\mathrm{T}}\end{array}$ & $\mathrm{p}$-value & $\begin{array}{c}\text { Ljung-Box } \\
\text { statistic } \\
\left\{\tilde{\mathrm{x}}_{\mathrm{i}} \hat{\psi}_{\mathrm{i}}^{-1}\right\}_{1}^{\mathrm{T}}\end{array}$ \\
\hline
\end{tabular}

\begin{tabular}{lrrrr}
6 d.f. & 7.79 & 0.254 & 8.89 & 0.180 \\
12 d.f. & 9.77 & 0.636 & 14.08 & 0.295 \\
18 d.f. & 17.48 & 0.491 & 21.38 & 0.261 \\
24 d.f. & 26.22 & 0.342 & 31.58 & 0.138 \\
\hline
\end{tabular}

${ }^{\mathrm{a}}$ Weibull ACD.

Lag order selected on the basis of LR, AIC and BIC statistic.

${ }^{b}$ Instruments used for orthogonality conditition in eq. [17] :

$\mathrm{Z}_{\mathrm{d}, \mathrm{i}-1}=\left(1, \tilde{\mathrm{x}}_{\mathrm{i}-1}, \ldots, \tilde{\mathrm{x}}_{\mathrm{i}-24}\right)$

Lag order $\mathrm{M}$ in eq. [14] : 24

Lag order $\mathrm{J}$ in eq. [36] : 24

Three iterations of GMM procedure. 
TABLE 3

GMM Estimation Results

Interdependent Model ${ }^{\mathrm{a}}$

\begin{tabular}{cc}
\hline GMM & Standard \\
Estimate & Error
\end{tabular}

Volatility Process

$\begin{array}{lll}\varpi_{\mathrm{h}} & 0.3256 & 0.0344 \\ \alpha_{\mathrm{h}} & 0.1128 & 0.0093 \\ \beta_{\mathrm{h}} & 0.8093 & 0.0145\end{array}$

Inter-Transaction

Duration Process

\begin{tabular}{ccc}
$\varpi_{\mathrm{d}}$ & 0.2185 & 0.0585 \\
$\alpha_{\mathrm{d}, 1}$ & 0.0735 & 0.0086 \\
$\alpha_{\mathrm{d}, 2}$ & -0.0141 & 0.0124 \\
$\beta_{\mathrm{d}, 1}$ & 0.6853 & 0.0740 \\
$\zeta_{1}$ & 0.0064 & 0.0022 \\
$\zeta_{2}$ & 0.0146 & 0.0034 \\
\hline Hansen $\chi^{2}$ test & \multicolumn{2}{c}{$\chi^{2}(137)=146.2$} \\
\end{tabular}

\footnotetext{
${ }^{\mathrm{a}}$ Instruments used for orthogonality conditition in eq. [27] :

$\mathrm{Z}_{\mathrm{d}, \mathrm{i}-1}=\left(1, \tilde{\mathrm{x}}_{\mathrm{i}-1}, \ldots, \tilde{\mathrm{x}}_{\mathrm{i}-24}, \mathrm{r}_{\mathrm{i}-1}^{2}, \mathrm{r}_{\mathrm{i}-2}^{2}, \ldots ., \mathrm{r}_{\mathrm{i}-24}^{2}\right)$

Instruments used for orthogonality condition in eq. [20] :

$\mathrm{Z}_{\mathrm{h}, \mathrm{i}-1}=\left(1, \mathrm{r}_{\mathrm{i}-1}, \ldots \mathrm{r}_{\mathrm{i}-24}, \mathrm{r}_{\mathrm{i}-1}^{2}, \mathrm{r}_{\mathrm{i}-2}^{2}, \ldots, \mathrm{r}_{\mathrm{i}-24}^{2}\right)$

Instruments used for orthogonality condition in eq. [22] :

$\mathrm{Z}_{\mathrm{m}, \mathrm{i}-1}=\left(1, \mathrm{r}_{\mathrm{i}-1}, \mathrm{r}_{\mathrm{i}-2}, . . \mathrm{r}_{\mathrm{i}-24}\right)$

Lag order $\mathrm{J}$ in eq. [25] : 24

Lag order $\mathrm{M}$ in eq. [36] : 24

Three iterations of GMM procedure.
} 